\title{
PERFIL DO LICENCIANDO \\ E SUA ESCOLHA PELA \\ CARREIRA DOCENTE: \\ UMA ANÁLISE LONGITUDINAL*
}

\author{
Geraldo Andrade da Silva Filho ${ }^{\text {I }}$ \\ Adriano Souza Senkevics II
}

http://dx.doi.org/10.24109/9788578630669.ceppe.v1a3

\section{RESUMO}

A importância do professor para o desempenho e a trajetória dos discentes é bastante reconhecida em pesquisas nacionais e internacionais. Em que pese a relevância da temática, persistem inúmeras perguntas a serem mais bem exploradas, tais como o quanto o perfil dos licenciandos se transforma, em uma perspectiva longitudinal, na entrada e na saída do curso de graduação, comparado ao daqueles que já exerciam ou que passaram a exercer atividade docente. Para avançar sobre essas lacunas, este estudo elabora um painel longitudinal que acompanha por quatro ou cinco anos - do ingresso à conclusão - todos os estudantes que ingressaram em cursos de licenciatura entre 2010 e 2011 no Brasil, por meio da junção de bases de dados do Instituto Nacional de Estudos e Pesquisas Educacionais Anísio Teixeira - Inep (Censo

* Os autores agradecem a Daniel Gama e Colombo, pela leitura crítica da versão inicial do texto, e a Izabel Costa da Fonseca que, no âmbito do Projeto BRA/15/002, estruturou os dois painéis longitudinais utilizados para a montagem da base utilizada neste artigo.

I Geraldo Andrade da Silva Filho é doutor em economia pela Escola de Economia de São Paulo, da Fundação Getúlio Vargas. É da carreira de Especialista em Políticas Públicas e Gestão Governamental em exercício no Instituto Nacional de Estudos e Pesquisas Educacionais Anísio Teixeira (Inep), atuando na Diretoria de Estudos Educacionais (Dired).

II Adriano Souza Senkevics é doutorando em educação pela Universidade de São Paulo (USP) e pesquisador do Instituto Nacional de Estudos e Pesquisas Educacionais Anísio Teixeira (Inep), atuando na Diretoria de Estudos Educacionais (Dired). 
da Educação Básica, Censo da Educação Superior, Exame Nacional do Ensino Médio - Enem e Exame Nacional de Desempenho de Estudantes - Enade) e do Ministério do Trabalho (Relação Anual de Informações Sociais - Rais). Em posse dessa base de dados, a análise divide os licenciandos em quatro grupos, tendo como critério o momento em que se vincularam ou não à carreira docente, se antes ou depois do ingresso no curso de licenciatura. Em seguida, são investigados, de maneira comparada, o perfil e o desempenho dos grupos de licenciandos em distintos momentos da graduação (ingresso, trajetória e conclusão), por meio de estatísticas descritivas e modelos de regressão linear múltipla.

Palavras-chave: avaliação do desempenho; educação superior; estudo longitudinal; formação de professores; licenciatura.

\section{INTRODUÇÃO}

Há muito se reconhece a importância do professor para a formação dos estudantes. Para confirmar essa afirmação, estudos apontam que os efeitos da atividade de um professor podem ser mensurados pela sua capacidade de afetar não apenas os resultados de curto prazo de seus alunos, exemplificados pelo desempenho em exames padronizados (Chetty; Friedman; Rockoff, 2014a), mas também pelos resultados de longo prazo, tais como os rendimentos auferidos por esses mesmos alunos na vida adulta (Chetty; Friedman; Rockoff, 2014b), consideradas todas as mediações necessárias. Sabe-se que, uma vez controladas as características socioeconômicas dos estudantes, o principal fator a explicar a variabilidade de proficiência entre alunos em testes padronizados é o efeito do professor (Rockoff, 2004; Rivkin; Hanushek; Kain, 2005; Moriconi, 2012). Ainda, de acordo com a literatura, o conhecimento específico do docente na disciplina que leciona é um dos fatores que explicam seu desempenho (Hanushek; Woessmann, 2012).

Em que pese a importância do recrutamento e da permanência de profissionais qualificados na docência, estudos mostraram que, nas últimas décadas, nos Estados Unidos, estudantes com níveis mais elevados de habilidades verbais e de conhecimentos em matemática, segundo as notas obtidas em testes padronizados, foram menos propensos a ingressar na carreira docente (Corcoran; Evans; Schwab, 2004). No Brasil, pesquisas têm mostrado que os ingressantes de cursos superiores associados à carreira docente apresentam, em média, desempenho inferior ao dos ingressantes dos demais cursos superiores e advêm de famílias com perfil socioeconômico menos privilegiado (Louzano et al., 2010; Brasil. Inep, 2009; 2010; Gatti; Barreto, 2009; Alves et al., 2016; Iede, 2018). De acordo com revisão de Bauer, Cassettari e Oliveira (2017, p. 946), esse fenômeno sugere uma dificuldade de a carreira docente atrair candidatos 
com desempenho suficientemente elevado no ensino médio (EM) a ponto de dispensar esforços adicionais, visando a compensar lacunas anteriores de formação. A título de ilustração, Silva Filho (2016) aponta para o baixo desempenho de graduandos em pedagogia no Exame Nacional do Ensino Médio - Enem, particularmente na prova de matemática e suas tecnologias, o que poderia indicar menor nível de conhecimento do conteúdo.

Entretanto, boa parte dos estudos feitos no Brasil, até o momento, apresentam análises de dados transversais (cross-section), carecendo ainda de estudos longitudinais que possam analisar o percurso formativo e o ingresso dos professores na carreira docente. Como exceções a esse quadro, em 2017, o Instituto Nacional de Estudos e Pesquisas Educacionais Anísio Teixeira (Inep) lançou indicadores de trajetória de curso de graduação, os quais têm mostrado que, à guisa de exemplo, de todos os cursos de pedagogia ofertados no território nacional, aproximadamente metade dos ingressantes de 2010 concluem o curso até cinco anos depois do início, ao passo que $41,8 \%$ desistem ao longo desse percurso. ${ }^{1} \mathrm{~A}$ despeito das contribuições de abordagens como essa, é preciso reconhecer que os indicadores divulgados pelo Inep, por estarem agregados em cursos, não possibilitam que os perfis de docentes e de potenciais docentes sejam relacionados às suas trajetórias ao longo da graduação e a medidas de valor adicionado pelo curso superior, bem como investigar se o perfil verificado no ingresso no ensino superior (ES) fica ainda menos ou mais privilegiado na saída do curso e na seleção para a carreira docente da educação básica. Rabelo e Cavenaghi (2016) inovaram ao utilizar dados longitudinais para mostrar a ocorrência de baixas taxas de conclusão nos cursos de licenciatura em matemática, química, biologia e física, e o aumento do tempo de conclusão nesses cursos entre os anos de 2009 e 2013. No entanto, apesar de trabalharem com dois painéis longitudinais, as autoras não uniram o painel do Censo da Educação Superior com o painel relativo a docentes oriundos do Censo da Educação Básica, um dos diferenciais do presente estudo. Ao juntarmos esses dois painéis longitudinais, somos capazes de identificar, entre os licenciandos, os que já se encontravam no exercício da docência e também o momento em que aqueles que não atuavam previamente como professores passaram a fazê-lo.

Utilizando dados em estrutura de painel longitudinal, pretende-se aprofundar a discussão sobre a seleção de docentes. O emprego dessa metodologia se justifica à luz da necessidade de compreender como o perfil de licenciados se constitui do início ao término do processo de formação para a carreira docente, tendo em vista que, no Brasil, a busca por uma colocação no mercado de trabalho, por parte dos futuros professores, se dá durante e depois de passarem por programas de formação universitária, e não exatamente antes de seu ingresso, como sugerido por Louzano et al.

1 Os indicadores de fluxo da educação superior do Inep estão disponíveis em: < http://portal.inep.gov.br/ web/guest/indicadores-educacionais > . Acesso em: 27 jul. 2018. 
(2010). Ao lado disso, é sabido que, apesar de o Brasil apresentar um volumoso corpo discente de licenciandos - de acordo com o Censo da Educação Superior, os cursos de licenciatura figuram entre os mais frequentados do país e representam cerca de sete mil dos 32 mil cursos ofertados em 2016 -, existe forte demanda por profissionais com formação específica para a área em que lecionam (Brasil. Inep, 2018). Essa constatação se soma à ausência desses docentes na rede pública tal como recorrentemente denunciado por gestores e pesquisadores da área (Pinto, 2014; Araujo; Vianna, 2011).

No presente estudo, nosso objetivo é desenvolver uma análise exploratória do perfil dos ingressantes nos cursos de educação superior relacionados à carreira docente, isto é, pedagogia e licenciaturas, nos anos de 2010 e 2011, comparando os ingressantes de acordo com o critério do momento em que se vincularam ou não à carreira docente. Para tanto, organizamos a base de dados em quatro grupos, de acordo com os seguintes critérios: aqueles que já exerciam função docente na educação básica, subdivididos entre os que permaneceram lecionando após o ingresso no ensino superior (grupo 1) e aqueles que interromperam a atividade docente (grupo 2), os que não eram professores, mas se tornaram docentes após o ingresso no ensino superior (grupo 3), e os que não seguiram a carreira docente (grupo 4), pelo menos até o ano de 2015, tal como apresentado no Quadro 1.

\section{QUADRO 1}

\section{GRUPO DE LICENCIANDOS EM FUNÇÃO DO EXERCÍCIO OU NÃO DA DOCÊNCIA ANTES OU DEPOIS DO INGRESSO NO CURSO DE ENSINO SUPERIOR - BRASIL - 2010/2011}

\begin{tabular}{|c|c|c|c|}
\hline GRUPO & $\begin{array}{c}\text { Docente antes do } \\
\text { ingresso no ES? }\end{array}$ & $\begin{array}{c}\text { Exerceu docência após } \\
\text { ingresso no ES? }\end{array}$ & Sigla \\
\hline $\mathbf{1}$ & Sim & Sim & S-S \\
\hline $\mathbf{2}$ & \multirow{2}{*}{ Não } & Não & S-N \\
\hline $\mathbf{3}$ & & Sim & N-S \\
\hline
\end{tabular}

Fonte: Elaboração própria com base nos dados do Censo da Educação Básica 2009-2015 e do Censo da Educação Superior 2010-2015.

Compararemos esses quatro grupos de ingressantes no ensino superior considerando as seguintes dimensões: (1) características demográficas e socioeconômicas no momento de ingresso; (2) desempenho no Enem no ano anterior ao ingresso (2009 ou 2010); (3) características da instituição em que frequentou o ES e sua trajetória ao longo do curso; e (4) desempenho no Exame Nacional de Desempenho dos Estudantes (Enade) no ano em que concluíram o ES (apenas para os concluintes em 2014). 


\section{METODOLOGIA E BASE DE DADOS}

\subsection{BASE DE DADOS}

Para elaboração das análises empreendidas neste estudo foi construída uma base de dados no formato de painel longitudinal multivariado (Singer; Willet, 2003) dos ingressantes avaliados no Enade 2014 em cursos superiores associados à docência na educação básica. Utilizando a identificação única de indivíduos - no caso, o número no Cadastro de Pessoas Físicas (CPF) - juntaram-se diversas bases de dados do Inep. Com base no Censo da Educação Superior foram obtidas informações sobre os ingressantes em 2010 e 2011 nos cursos superiores de licenciaturas e de bacharelados relacionados às licenciaturas, selecionados conforme art. $1^{\circ}$ da Portaria Normativa $\mathrm{n}^{\mathrm{o}} 8$ do Ministério da Educação, de 14 de março de 2014, que definiu os cursos avaliados no Enade daquele ano. Assim, coube neste artigo investigar os estudantes e as características de seus respectivos cursos: (1) que conferem diploma de bacharel ou licenciatura em: a) ciência da computação; b) ciências biológicas; c) ciências sociais; d) filosofia; e) física; f) geografia; g) história; h) letras-português; i) matemática; e j) química; e (2) os que conferem diploma de licenciatura em a) artes visuais; b) educação física; c) letras-português e espanhol; d) letras-português e inglês; e) música; e f) pedagogia.

A base de dados longitudinal construída permite acompanhar a coorte de ingressantes em cursos superiores em 2010 e 2011 em instituições de ensino superior (IES) até a conclusão do curso. Para simplificar e facilitar as análises na construção do painel, acompanhamos cada estudante em até dois cursos superiores. Não consideramos se esse estudante já frequentava ou veio a frequentar outro curso em diferentes anos. Construiu-se a trajetória desses ingressantes ao longo do curso até sua formatura ou abandono, no período entre 2010 e 2015. Procuramos esses ingressantes no Enem 2009 e 2010, optando pela edição mais próxima ao ano de ingresso no caso de o estudante ter prestado as duas edições da prova, acrescentando à base longitudinal dos ingressantes suas notas e características individuais informadas no ato de inscrição no exame. Para os estudantes que não abandonaram o curso superior e que o concluíram em 2014, buscamos no Enade do mesmo ano informações sobre seu desempenho nos testes e, no questionário do estudante, suas impressões sobre o curso e seus planos para o futuro. Adicionalmente, por meio do Censo da Educação Básica, identificamos todos os indivíduos do painel que, ao longo do período entre 2009-2015, lecionaram em escolas de educação básica, e obtivemos a informação sobre se o docente já possuía curso superior ao ingressar na licenciatura. Por fim, acrescentamos ao painel a informação da Rais sobre o início do contrato de trabalho dos docentes.

Para as análises que se seguem, os grupos de licenciandos serão referidos pela numeração e sigla expostas no Quadro 1. Recomendamos regressar a tal quadro sempre que necessário para a compreensão do texto. 


\subsection{ESTATÍSTICAS DESCRITIVAS}

A Tabela 1 apresenta o quantitativo de estudantes classificados nos quatro grupos de interesse deste estudo. Um total de 925.281 estudantes foi identificado em nosso painel longitudinal, sendo que 4,6\% ingressaram em dois cursos superiores de interesse do estudo, em 2010 e 2011. Diante dos objetivos de entender a trajetória de licenciandos, a construção do painel privilegiou os cursos de licenciatura, assim, naturalmente, a grande maioria dos indivíduos, 803.160 (86,8\%), frequentava algum curso de licenciatura. O grupo mais numeroso (64,4\% dos licenciandos), indicado como grupo 4 na Tabela 1, é o de estudantes que não exerciam a docência antes do ingresso no ES em 2010 ou 2011 e que continuaram não exercendo após o ingresso, pelo menos até o limite do período de análise compreendido no painel (2015). O segundo grupo mais numeroso (24,1\% dos licenciandos), denominado grupo 3 , é o de indivíduos que não exerciam a docência quando ingressaram no ES, mas passaram a atuar como docentes após o ingresso no ES ou após o concluírem. Os estudantes que exerciam a docência antes do ingresso no ensino superior correspondem a 11,5\% do total de licenciandos. O grupo 1 corresponde aos que não abandonaram a docência após o ingresso no ES, com 10,1\% dos licenciandos, enquanto o grupo 2, correspondendo a $1,4 \%$ de licenciandos, representa os que deixaram de lecionar em algum momento após ter ingressado no ES.

TABELA 1

CARACTERIZAÇÃO DOS GRUPOS DE ESTUDANTES INGRESSANTES NOS CURSOS DE INTERESSE - BRASIL - 2010/2011

\begin{tabular}{|c|c|c|c|c|c|c|c|}
\hline \multirow{2}{*}{ GRUPO } & \multicolumn{2}{|c|}{ Total } & \multicolumn{2}{|c|}{ Licenciandos } & \multirow{2}{*}{$\begin{array}{c}(\mathrm{B}) /(\mathrm{A}) \\
\%\end{array}$} & \multicolumn{2}{|c|}{$\begin{array}{l}\text { Licenciandos a } \\
\text { distância }\end{array}$} \\
\hline & Freq. (A) & $\%$ & Freq. (B) & $\%$ & & $\begin{array}{l}\text { Freq. } \\
\text { (C) }\end{array}$ & $\begin{array}{c}(\mathrm{C}) /(\mathrm{B}) \\
\%\end{array}$ \\
\hline 1 (S-S) & 83.397 & 9,0 & 81.517 & 10,1 & 97,7 & 47.199 & 57,9 \\
\hline $2(\mathrm{~S}-\mathrm{N})$ & 11.564 & 1,3 & 11.071 & 1,4 & 95,7 & 5.781 & 52,2 \\
\hline 3 (N-S) & 202.568 & 21,9 & 193.680 & 24,1 & 95,6 & 67.826 & 35,0 \\
\hline $4(\mathrm{~N}-\mathrm{N})$ & 627.752 & 67,8 & 516.892 & 64,4 & 82,3 & 137.889 & 26,7 \\
\hline Total & 925.281 & 100 & 803.160 & & 86,8 & 258.695 & 32,2 \\
\hline
\end{tabular}

Fonte: Censo da Educação Básica 2009-2015, Censo da Educação Superior 2010-2015. Elaboração própria.

Os estudantes que em algum momento de sua trajetória estiveram em sala de aula lecionando para turmas da educação básica com mais frequência se engajaram em cursos de licenciatura. Da amostra total, 96,2\% dos que em algum momento exerceram a docência, ingressaram em alguma licenciatura. Em contraste, entre os que não exerceram a docência, pelo menos no período coberto pelo painel (2009-2015), 
82,3\% ingressaram em licenciatura. A grande maioria dos estudantes que exerciam atividade docente na educação básica no ano anterior ao ingresso no ensino superior $(97,5 \%)$ matriculou-se em um curso de licenciatura. Dos que não exerciam a docência na educação básica, 24,4\% passaram a exercê-la em algum momento após o ingresso no ES. Desses que passaram a atuar como docentes, 95,6\% ingressaram em um curso de licenciatura.

Mais frequentemente, os indivíduos que exercem a docência optam pela modalidade a distância, provavelmente pela restrição de tempo presencial para os estudos ou pela distância de sua residência ou local de trabalho à IES mais próxima. Quase um terço dos licenciandos cursava a modalidade a distância, com destaque para os que exerciam a docência previamente. Dos docentes que ingressaram em licenciatura, $55,8 \%$ optaram pela modalidade a distância, em contraste com $29,0 \%$ dos que não atuavam na docência.

TABELA 2

\section{ANO DE INGRESSO, INFORMAÇÕES DE FLUXO E CONCLUSÃO DOS LICENCIANDOS -} BRASIL - 2010/2011

\begin{tabular}{|c|c|c|c|c|c|c|c|c|}
\hline \multirow[b]{2}{*}{ GRUPO } & \multicolumn{2}{|c|}{ Ano ingresso } & \multicolumn{2}{|c|}{ Abandonaram } & \multicolumn{2}{|c|}{ Trancaram } & \multicolumn{2}{|c|}{ Graduados } \\
\hline & $\begin{array}{c}2010 \\
\text { (D) }\end{array}$ & $\begin{array}{c}2011 \\
(E)\end{array}$ & $\begin{array}{l}\text { Freq. } \\
\text { (F) }\end{array}$ & $\begin{array}{l}(\mathrm{F}) / \\
(\mathrm{B})\end{array}$ & $\begin{array}{l}\text { Freq. } \\
\text { (G) }\end{array}$ & $(G) /(B)$ & $\begin{array}{c}\text { Freq. } \\
\text { (H) }\end{array}$ & $\begin{array}{c}(\mathbf{H}) /(\mathbf{B}) \\
\%\end{array}$ \\
\hline 1 (S-S) & 42.832 & 38.685 & 17.469 & 21,4 & 4.040 & 5,0 & 40.941 & 50,2 \\
\hline $2(\mathrm{~S}-\mathrm{N})$ & 5.553 & 5.518 & 3.071 & 27,7 & 665 & 6,0 & 4.792 & 43,3 \\
\hline 3 (N-S) & 108.281 & 85.399 & 33.006 & 17,0 & 6.923 & 3,6 & 123.398 & 63,7 \\
\hline $4(\mathrm{~N}-\mathrm{N})$ & 251.378 & 265.514 & 245.081 & 47,4 & 43.978 & 8,5 & 172.714 & 33,4 \\
\hline Total & 408.044 & 395.116 & 298.627 & 37,2 & 55.606 & 6,9 & 341.845 & 42,6 \\
\hline
\end{tabular}

Fonte: Censo da Educação Básica 2009-2015, Censo da Educação Superior 2010-2015. Elaboração própria.

Nota 1: A taxa de formados (concluintes) não corresponde à taxa de conclusão de cursos porque neste estudo consideramos como unidade de análise o indivíduo, não a matrícula, como normalmente se considera quando se analisa taxa de conclusão de cursos. Nota 2: (B) refere-se ao total de licenciandos apresentado na Tabela 1.

A Tabela 2 apresenta informações referentes ao ano de ingresso e de conclusão, ao abandono e ao trancamento do curso. Entre os quatro grupos existem diferenças na distribuição dos estudantes pelo ano de ingresso, sendo essa distribuição mais próxima quando se compara os que exerciam com os que não exerciam a docência no momento prévio ao ingresso. Interessante notar que a proporção de graduados em licenciatura é significativamente maior entre os que eram docentes do que entre os que não eram, 49,4\% (50,2\% para os que continuaram na docência e 43,3\% entre os que deixaram a sala e aula) versus $41,7 \%$, respectivamente. Entre os que não exerciam a docência, $63,7 \%$ dos que passaram a lecionar após entrar no curso de licenciatura concluíram o curso, versus 33,4\% dos que não ingressaram na carreira docente. Essa diferença era esperada, pois muitas vezes exige-se diploma do ES para o ingresso 
na carreira do magistério e parte considerável dos ingressantes no ES, em 2010 e 2011, não possuía diploma. Além de, em média, concluírem a graduação em menor tempo, os docentes também abandonam ou trancam o curso menos frequentemente. Dos que exerciam a docência ao ingressar no curso superior, 26,6\% o abandonaram ou trancaram, em comparação a 39,6\% nessa situação entre os não docentes.

A Tabela 3 reúne estatísticas descritivas sobre características relativas aos indivíduos das bases de dados estudadas. Com base no levantamento de matrículas do Censo da Educação Superior, vê-se que cerca de 70\% dos mais de 800 mil licenciandos pertencem ao sexo feminino, quase $1 / 4$ se autodeclarou branco ou amarelo, e aproximadamente 15\% são provenientes do ensino médio privado; em média, eles ingressam na idade de 27,8 anos. No entanto, evidencia-se que os dados ausentes (missing) para cor/ raça e categoria administrativa da escola de origem alcançam valores aproximados de, respectivamente, $56 \%$ e $44 \%$. A mesma tabela apresenta a frequência dessas características entre a amostra de licenciandos que serão considerados adiante nas análises envolvendo o Enem e o Enade, isto é, os estudantes que tiveram notas computadas para as provas consideradas neste estudo. Se compararmos os quatro grupos de licenciandos, vê-se que, de modo geral, os maiores contrastes encontram-se entre o grupo 1 e o grupo 4, os quais serão explorados mais detidamente nas análises apresentadas à frente.

TABELA 3

\section{CARACTERÍSTICAS INDIVIDUAIS DOS LICENCIANDOS, NO GERAL, E ENTRE AQUELES COM NOTA NO ENEM E NO ENADE - BRASIL - 2010/2011}

(continua)

\begin{tabular}{|c|c|c|c|c|c|c|}
\hline \multirow{2}{*}{ Base } & \multirow{2}{*}{ Variável } & \multicolumn{5}{|c|}{ GRUPO } \\
\hline & & 1 (S-S) & $2(\mathrm{~S}-\mathrm{N})$ & $3(\mathrm{~N}-\mathrm{S})$ & $4(\mathrm{~N}-\mathrm{N})$ & Total \\
\hline \multirow{6}{*}{ ఝ } & Sexo masculino (\%) & 15,7 & 16,2 & 19,3 & 35,6 & 29,4 \\
\hline & Cor/raça branca ou amarela (\%) & 18,5 & 18,7 & 25,8 & 24,8 & 24,3 \\
\hline & missing cor/raça (\%) & 64,7 & 62,9 & 54,5 & 55,4 & 56,2 \\
\hline & EM na rede privada (\%) & 11,1 & 11,9 & 13,2 & 16,1 & 14,8 \\
\hline & missing rede EM (\%) & 54,7 & 52,7 & 41,5 & 43,7 & 44,4 \\
\hline & Idade média (anos) & 34,8 & 33,3 & 27,1 & 26,8 & 27,8 \\
\hline \multirow{5}{*}{ 롤 } & Licenciandos com nota (\%) & 10,6 & 15,8 & 37,1 & 42,9 & 37,8 \\
\hline & Sexo masculino (\%) & 18,9 & 21,0 & 22,8 & 37,5 & 33,4 \\
\hline & Cor/raça branca ou amarela (\%) & 40,3 & 38,7 & 45,4 & 46,3 & 45,9 \\
\hline & EM na rede privada (\%) & 7,9 & 8,8 & 10,2 & 18,3 & 16,1 \\
\hline & Idade média (anos) & 30,1 & 27,9 & 23,0 & 23,2 & 23,4 \\
\hline
\end{tabular}


TABELA 3

CARACTERÍSTICAS INDIVIDUAIS DOS LICENCIANDOS, NO GERAL, E ENTRE AQUELES COM NOTA NO ENEM E NO ENADE - BRASIL - 2010/2011

\begin{tabular}{|c|c|c|c|c|c|c|}
\hline \multirow{2}{*}{ Base } & \multirow{2}{*}{ Variável } & \multicolumn{5}{|c|}{ GRUPO } \\
\hline & & $1(\mathrm{~S}-\mathrm{S})$ & $2(\mathrm{~S}-\mathrm{N})$ & $3(\mathrm{~N}-\mathrm{S})$ & $4(\mathrm{~N}-\mathrm{N})$ & Total \\
\hline \multirow{5}{*}{$\underset{\text { 뵈 }}{\stackrel{0}{Z}}$} & Licenciandos com nota (\%) & 14,2 & 13,5 & 19,8 & 13,7 & 15,2 \\
\hline & Sexo masculino (\%) & 12,0 & 12,4 & 16,8 & 27,8 & 22,7 \\
\hline & Cor/raça branca ou amarela (\%) & 44,9 & 46,1 & 48,7 & 48,1 & 47,9 \\
\hline & EM na rede privada (\%) & 10,5 & 9,5 & 11,5 & 16,4 & 14,2 \\
\hline & Idade média (anos) & 34,2 & 32,5 & 25,9 & 26,1 & 26,9 \\
\hline
\end{tabular}

Fonte: Elaboração própria com base em dados do Censo da Educação Básica 2009-2015, do Censo da Educação Superior 2010-2015, do Enem 2009-2010 e do Enade 2014.

Nota 1: Não foram apresentados os missings para o Enem e o Enade em razão de serem bastante reduzidos (inferiores a 3\%). Nota 2: Para o Enem, informaçõs de sexo, cor/raça e rede privada no EM foram obtidas via questionário e, em caso de missing, complementadas com o Censo da Educação Superior.

\subsection{ESTRATÉGIA EMPÍRICA}

Conforme já exposto, este trabalho apresenta resultados exploratórios em que utilizamos estatísticas descritivas simples tais como médias, proporções, descrição das distribuições estatísticas de cada grupo de interesse e participação desses grupos em partições das distribuições de notas no Enem. Além da análise de diferenças de médias simples, este estudo também compara as médias dos grupos de forma condicional às características de seus componentes, como no modelo a seguir:

$$
\begin{aligned}
y_{i}=\alpha+ & \gamma \cdot \text { Grupo }_{j}+\tau \cdot \text { ano }+\sum_{k} \beta_{k} \cdot \text { caract_estudantes }_{k}+\sum_{n} \theta_{n} \cdot \text { caract_curso }_{n} \\
& +\sum_{m=1}^{4} \delta_{m} \cdot \text { desempenho_pregresso } \text { dere }_{m}+\varepsilon_{i}
\end{aligned}
$$

Em que: (1) o grupo de referência é composto pelos estudantes de licenciatura que não exerciam a docência antes do ingresso no curso superior nem exerceram após esse ingresso, e Grupo ${ }_{i}$, em que $\mathrm{j}=1,2,3$, representa os três demais grupos de interesse; (2) ano representa uma variável indicadora para distinguir os estudantes que ingressaram em 2010 (Enem 2009) ou ingressaram em 2011 (Enem 2010); (3) caract_estudantes $_{k}$ representa o vetor de $k$ características dos estudantes e de suas respectivas famílias; e (4) caract_curso ${ }_{n}$ representa o vetor de $n$ características do curso e instituição em que o estudante está matriculado, incluindo um vetor de variáveis indicadoras da unidade da federação de localização da instituição. Em algumas especificações das regressões destinadas a analisar o desempenho dos estudantes no Enade, inclui-se o vetor (desempenho_ pregresso $_{m}$ ) com as notas do estudante nas quatro 
provas objetivas do Enem. O modelo fica completo com a inclusão do termo de erro idiossincrático $\left(\varepsilon_{\mathrm{i}}\right)$. Por fim, nas análises do desempenho do estudante ao final da licenciatura, em algumas especificações, incluímos variáveis para capturar os efeitos fixos de curso e instituição, de modo a permitir comparação dos desempenhos dos estudantes em relação aos seus pares dentro de determinado curso, instituição e turno.

\section{PERFIL E DESEMPENHO DOS LICENCIANDOS EM DISTINTOS MOMENTOS DA GRADUAÇÃO}

Nesta seção, compararemos os desempenhos dos indivíduos dos quatro grupos de interesse na edição do Enem imediatamente anterior ao ano de ingresso no ES e no Enade 2014. Ademais, aprofundaremos as análises comparadas das características individuais associadas ao tipo de curso e instituição em que o indivíduo ingressou e sua trajetória ao longo da graduação. O conjunto das análises contará com estatísticas descritivas e com a aplicação de modelos de regressão linear múltipla com estimação por meio do método de mínimos quadrados ordinários. As regressões permitem, além da comparação das médias entre os grupos - para o que se adotou o grupo 4 como referência -, encontrar diferenças entre eles, controladas as características sociodemográficas dos estudantes e, quando pertinente, dos cursos e instituições em que estudam.

\subsection{COMPARAÇÃO DOS PERFIS NO INGRESSO EM CURSOS DE LICENCIATURA}

Nesta subseção apresentaremos análises descritivas do perfil dos estudantes no momento de ingresso no curso de licenciatura. Dentre os cursos avaliados no Enade 2014, como apresentado na Tabela 4, o com maior quantitativo de estudantes ingressantes em 2010 e 2011 é pedagogia, que concentra 45,3\% dos ingressantes em licenciaturas, seguido por educação física (10,5\% dos ingressantes em 2010 e 2011) e por letras (9,8\%). Entre os que exerciam a docência (grupos 1 e 2), 65,5\% ingressaram em pedagogia, contra 42,7\% dos que não atuavam na docência (grupo 3 e 4). Comparando os cursos em que ingressaram docentes e não docentes, percebe-se uma menor participação dos docentes em cursos da área de ciências da natureza e matemática e computação, 5,4\% docentes em oposição a 12,7\% não docentes e 5,6\% a 7,8\%, respectivamente.

Nos cursos da área de ciências da natureza, dentre os que não exerciam a docência ao ingressar no ES uma proporção menor de licenciandos inicia a docência após ingressar ou concluir o curso superior (30,9\%), quando comparados aos da área de ciências humanas (39,2\%), linguagens e códigos (42,3\%), matemática e computação $(42,9 \%)$, e pedagogia $(61,7 \%)$. 
TABELA 4

\section{DISTRIBUIÇÃO DOS INGRESSANTES DOS GRUPOS ANALISADOS, POR ÁREA E CURSO DE LICENCIATURA - BRASIL - 2010/2011 (EM \%)}

\begin{tabular}{|c|c|c|c|c|c|c|c|}
\hline \multirow{2}{*}{ Área/Curso } & \multicolumn{6}{|c|}{ GRUPO } & \multirow{2}{*}{ Total } \\
\hline & 1 (S-S) & $2(\mathrm{~S}-\mathrm{N})$ & $1+2$ & $3(\mathrm{~N}-\mathrm{S})$ & $4(\mathrm{~N}-\mathrm{N})$ & $3+4$ & \\
\hline Pedagogia & 65,7 & 64,1 & 65,5 & 58,9 & 36,6 & 42,7 & 45,3 \\
\hline Linguagens e códigos & 14,2 & 16,2 & 14,4 & 19,0 & 25,9 & 24,0 & 22,9 \\
\hline Letras & 8,1 & 8,8 & 8,2 & 9,5 & 10,1 & 10,0 & 9,8 \\
\hline Artes & 3,5 & 2,4 & 3,4 & 1,9 & 1,5 & 1,6 & 1,8 \\
\hline Educação física & 2,2 & 4,3 & 2,4 & 6,9 & 13,3 & 11,6 & 10,5 \\
\hline Música & 0,4 & 0,7 & 0,4 & 0,7 & 1,0 & 0,9 & 0,9 \\
\hline Ciências humanas & 9,1 & 8,5 & 9,1 & 9,2 & 14,2 & 12,8 & 12,4 \\
\hline História & 4,5 & 4,4 & 4,5 & 4,8 & 7,2 & 6,6 & 6,3 \\
\hline Geografia & 2,6 & 2,1 & 2,5 & 2,6 & 3,7 & 3,4 & 3,3 \\
\hline Filosofia & 1,3 & 1,3 & 1,3 & 1,0 & 1,9 & 1,6 & 1,6 \\
\hline Ciências sociais & 0,8 & 0,8 & 0,8 & 0,7 & 1,4 & 1,2 & 1,1 \\
\hline Ciências da natureza & 5,4 & 5,4 & 5,4 & 6,7 & 14,9 & 12,7 & 11,8 \\
\hline Biologia & 2,6 & 3,2 & 2,6 & 3,8 & 8,6 & 7,3 & 6,8 \\
\hline Física & 1,7 & 1,1 & 1,6 & 1,3 & 2,7 & 2,3 & 2,2 \\
\hline Química & 1,2 & 1,1 & 1,2 & 1,6 & 3,6 & 3,1 & 2,9 \\
\hline Matemática e computação & 5,6 & 5,7 & 5,6 & 6,3 & 8,3 & 7,8 & 7,5 \\
\hline Matemática & 4,9 & 4,8 & 4,9 & 6,0 & 7,5 & 7,0 & 6,8 \\
\hline Computação & 0,7 & 0,8 & 0,8 & 0,3 & 0,9 & 0,7 & 0,7 \\
\hline Total & 100,0 & 100,0 & 100,0 & 100,0 & 100,0 & 100,0 & 100,0 \\
\hline
\end{tabular}

Fonte: Elaboração própria com base em dados do Censo da Educação Básica 2009-2015 e do Censo da Educação Superior 2010-2015.

A Tabela 5 apresenta características das IES e dos cursos de graduação, segundo os quatro grupos considerados. Com relação à categoria administrativa das instituições, percebe-se que cerca de um terço dos licenciandos que já exerciam docência antes do ingresso no nível superior matricularam-se em IES públicas, ao passo que esse percentual se eleva para $41,3 \%$ no grupo 4 , referente aos licenciandos que não se iniciaram na docência em nenhum momento da trajetória analisada. De modo geral, esses números confirmam que a maioria $(62,7 \%)$ dos licenciandos, no Brasil, ingressam em instituições privadas, podendo este percentual aumentar a depender de outros atributos do estudante não explorados neste texto. No tocante à organização acadêmica da instituição, há poucas diferenças entre os grupos, podendo-se destacar o grupo 3 como o único que apresentou menos de $60 \%$ dos estudantes matriculados em universidades, o que pode estar relacionado ao fato de que este também é o grupo que menos ingressa em IES públicas, as quais são mais comumente credenciadas como universidades. 
TABELA 5

\section{FREQUÊNCIA DOS INGRESSANTES, SEGUNDO CARACTERÍSTICAS DA IES E DO CURSO DE LICENCIATURA - BRASIL - 2010/2011}

\begin{tabular}{|c|r|r|r|r|r|r|r|r|}
\hline \multirow{2}{*}{ GRUPO } & \multicolumn{4}{|c|}{ Características da IES } & \multicolumn{3}{c|}{ Características do curso } \\
\cline { 2 - 10 } & \multicolumn{2}{|c|}{ Pública } & \multicolumn{2}{|c|}{ Universidade } & \multicolumn{2}{|c|}{ Presencial } & \multicolumn{2}{|c|}{ Noturno $^{1}$} \\
\cline { 2 - 10 } & Freq. (I) & $(\mathbf{I}) /(B) \%$ & Freq. (J) & (J)/(B) \% & $\begin{array}{c}\text { Freq. } \\
\text { (K) }\end{array}$ & $\begin{array}{c}\text { (K)/(B) } \\
\%\end{array}$ & Freq. (L) & $\begin{array}{c}\text { (L)/(B) } \\
\%\end{array}$ \\
\hline $\mathbf{1}$ (S-S) & 26.125 & 32,0 & 53.530 & 65,7 & 33.995 & 41,7 & 59.356 & 72,8 \\
\hline $\mathbf{2}$ (S-N) & 3.490 & 31,5 & 6.912 & 62,4 & 5.249 & 47,4 & 8.143 & 73,6 \\
\hline $\mathbf{3}$ (N-S) & 56.832 & 29,3 & 109.474 & 56,5 & 125.183 & 64,6 & 143.427 & 74,1 \\
\hline $\mathbf{4}$ (N-N) & 213.284 & 41,3 & 323.133 & 62,5 & 378.104 & 73,1 & 368.684 & 71,3 \\
\hline Total & 299.731 & 37,3 & 493.049 & 61,4 & 542.531 & 67,5 & 579.610 & 72,2 \\
\hline
\end{tabular}

Fonte: Elaboração própria com base em dados do Censo da Educação Básica 2009-2015 e do Censo da Educação Superior 2010-2015.

Nota: ${ }^{1}$ Turno predominante cursado pelo estudante ao longo de sua graduação.

Com relação às características dos cursos frequentados, é notório que, entre os licenciandos que atuavam como docentes antes e depois do ingresso no nível superior (grupo 1), somente 41,7\% ingressaram em cursos presenciais, enquanto $73,1 \%$ dos licenciandos que não exerceram docência em nenhum momento do período considerado (grupo 4) estudaram em cursos dessa modalidade. Esse dado pode sugerir maior inclinação dos docentes em exercício a buscarem diplomas de licenciatura em cursos a distância, possivelmente como estratégia para compatibilizar sua jornada de trabalho com o programa de estudos. Também é possível notar que, independentemente do grupo, mais de $70 \%$ dos licenciandos estudaram predominantemente no período noturno, sem grandes diferenças entre os quatro grupos analisados.

\subsection{COMPARAÇÃO DOS DESEMPENHOS NO INGRESSO}

Iniciaremos esta subseção com análises descritivas sobre o desempenho dos licenciandos na edição do Enem imediatamente anterior ao seu ano de ingresso - a título de ilustração, caso o estudante tenha ingressado em 2010, consideraremos suas notas no Enem 2009. Como uma síntese de seu desempenho, calculamos a média aritmética simples das notas nas quatro provas objetivas do Enem. Quando pertinente, comparamos a distribuição da nota dos ingressantes em licenciatura com os demais participantes das mesmas edições do exame.

De um quantitativo de 803.160 licenciandos, obtivemos 303.935 indivíduos $(37,8 \%)$ com desempenho computado nas quatro áreas de conhecimento da edição do Enem anterior ao seu ingresso, sendo 142.674 referentes ao Enem 2009 e 161.261 ao Enem 2010. É importante mencionar que este é o universo de análise para os resultados explorados nesta seção. Na Tabela 3, apresentada anteriormente, exibimos as 
frequências relativas de licenciandos com média no Enem, computada segundo os quatro grupos comparados neste estudo. Na mesma tabela, observa-se o grande diferencial de participação no Enem entre os grupos, com uma notória sub-representação dos grupos 1 e 2. É possível aventar que isso se deve provavelmente à maior participação dos docentes em exercício nas IES privadas e a formas de ingresso menos condicionadas ao Enem, especialmente no período considerado neste estudo. Em que pese essas considerações, não exploraremos esses diferenciais.

Em uma visão geral do desempenho no Enem entre os quatro grupos, representada por um boxplot (Gráfico 1), observa-se forte sobreposição da principal porção da distribuição das notas. Suas medianas - representadas pelas linhas pretas no centro das caixas - encontram-se entre as notas médias de 500 e 550, tendo o grupo 4 apresentado a maior mediana e uma distribuição levemente deslocada para os valores superiores; por outro lado, também foi este o grupo que apresentou maior dispersão das notas, observável pelo padrão de distribuição que contempla a maior parte da escala apresentada no gráfico.

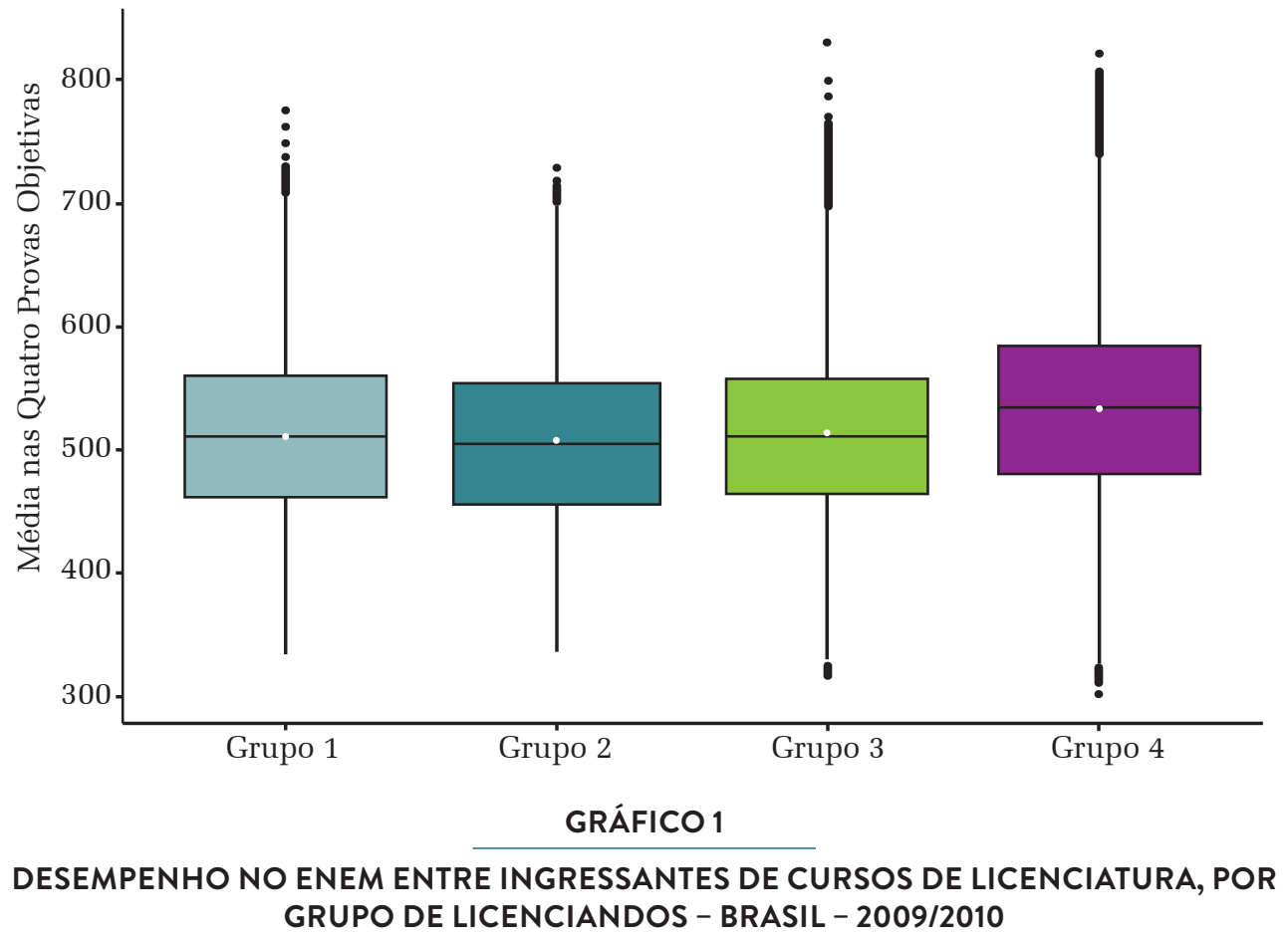

Fonte: Elaboração própria com base em dados do Enem 2009-2010, do Censo da Educação Básica $2010-2011$ e do Censo da Educação Superior 2010-2011.

Para explorarmos adicionalmente a distribuição das notas médias pelos quatro grupos, efetuamos uma comparação de seus desempenhos com a nota média de todos os participantes do Enem nas respectivas edições consideradas. Para tanto, repartimos em algumas frações o desempenho de todos os participantes com notas computadas 
para as quatro provas objetivas do Enem 2009 e 2010, e apresentamos no Gráfico 2 o percentual, dentro de cada grupo de licenciandos, distribuídos pelos quartos e pelo último décimo da proficiência geral. Os dados reafirmam que o grupo 4 apresenta o maior desempenho, tendo em vista que $35,1 \%$ dos licenciandos neste grupo encontram-se no $4^{\circ}$ quarto de desempenho no Enem - sem mencionar os 11,7\% no $10^{\circ}$ décimo -, ao passo que somente $13,8 \%$ deles encontram-se no $1^{\circ}$ quarto. Esses resultados apontam que há sobrerrepresentação do grupo 4 entre os participantes de maior desempenho no referido exame.

Quantis de desempenho geral no Enem (2009-2010)

40,0

$\because 1^{\mathrm{o}}$ quartil $\square 2^{\mathrm{o}}$ quartil $\square 3^{\mathrm{o}}$ quartil $\square 4^{\mathrm{o}}$ quartil $\backsim 10^{\circ}$ decil

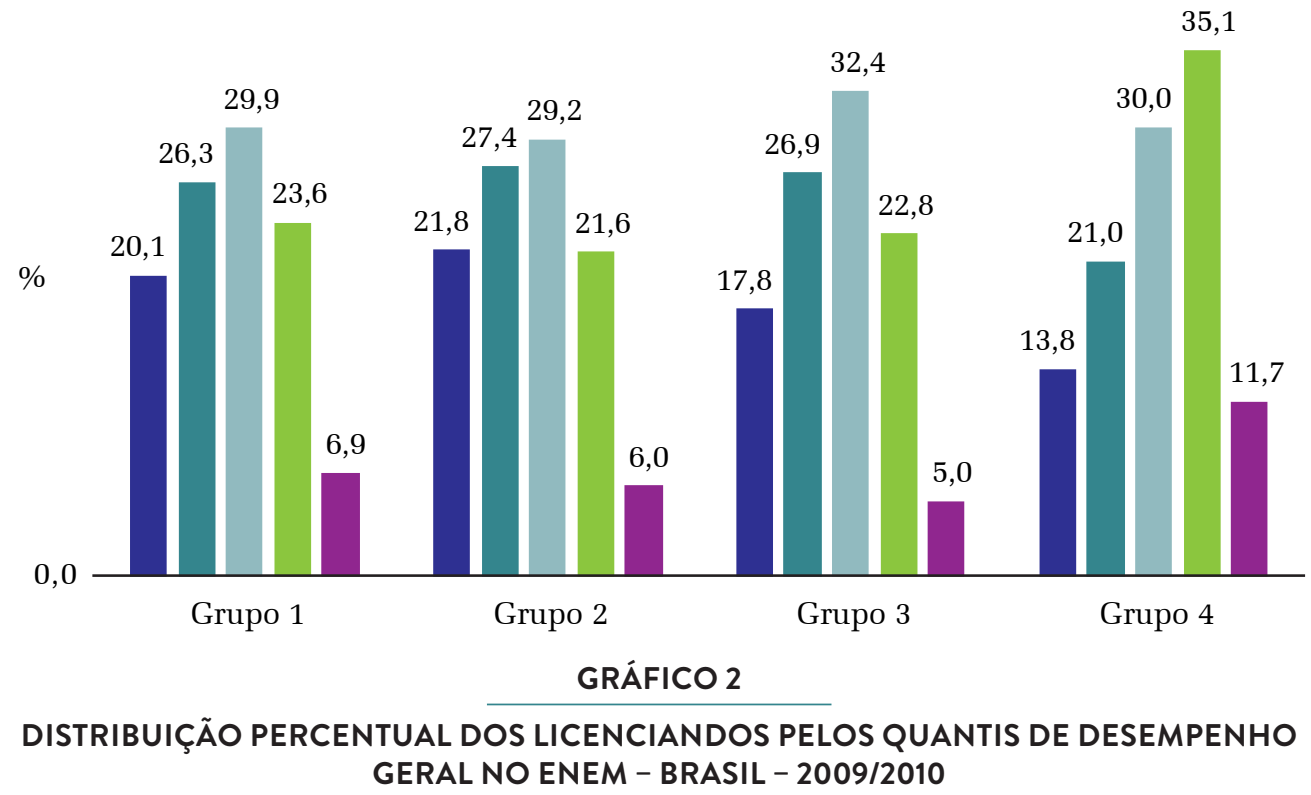

Fonte: Elaboração própria com base em dados do Enem 2009-2010, do Censo da Educação Básica 2010-2011 e do Censo da Educação Superior 2010-2011.

No lado oposto, os licenciandos que exerciam docência antes e depois do ingresso no curso de licenciatura (grupo 1) apresentam somente $23,6 \%$ de seus licenciados no $4^{\circ}$ quarto e $6,9 \%$ no último décimo da distribuição, ao mesmo tempo em que $20,1 \%$ deles encontram-se no $1^{\circ}$ quarto. O grupo 3 , por sua vez, apresenta um padrão mais próximo daquele de licenciandos que já exerciam docência antes do ingresso, se comparado ao grupo 4, apresentando baixo percentual de estudantes no $10^{\circ}$ décimo de desempenho e uma concentração entre o $2^{\circ}$ e o $3^{\circ}$ quarto. Ressalta-se que, nesse gráfico, estamos comparando o desempenho de estudantes que ingressaram no ensino superior com a proficiência geral dos participantes do exame - quer tenham conquistado uma vaga no ensino superior, quer estivessem apenas buscando certificação do ensino médio. Isso nos ajuda a entender o porquê de nenhum dos quatro grupos de 
licenciandos ter apresentado sobrerrepresentação de estudantes no quarto de menor desempenho no Enem (o qual possivelmente é ocupado por participantes que não obtiveram notas suficientemente altas para ingressarem em um curso de nível superior ou buscavam apenas a certificação).

Para aprofundar as análises do desempenho dos ingressantes, estimamos um modelo de regressão que considerou, como variável dependente, a média das notas nas quatro provas objetivas do Enem (apresentada em sua escala intervalar original) e, como variáveis independentes, um conjunto de informações demográficas e socioeconômicas dos licenciandos declaradas no Enem e no Censo da Educação Superior, bem como o seu pertencimento a um dos quatro grupos aqui analisados (Tabela 6). Com essa análise, objetivamos compreender o desempenho no momento de ingresso no curso de licenciatura, por meio da comparação entre estar ou não em exercício de docência antes e depois do ingresso, condicionada às características dos estudantes, tais como: sexo, cor/raça, idade, estado civil, localização da residência, dependência administrativa da escola em que frequentou o ensino fundamental e o ensino médio, escolaridade da mãe e do pai $^{2}$ e, finalmente, o grupo a que o licenciando pertence. Por motivo de eliminação dos casos que apresentavam missing para alguma variável do modelo, foram estimados os coeficientes de regressão para 264.263 licenciandos (87\%) de um total de 303.935 com média computada do Enem 2009 ou 2010.

TABELA 6

\section{REGRESSÃO LINEAR MÚLTIPLA DOS FATORES ASSOCIADOS AO DESEMPENHO NO ENEM ENTRE INGRESSANTES EM LICENCIATURAS - BRASIL - 2010/2011}

(continua)

\begin{tabular}{|c|c|c|c|}
\hline $\begin{array}{c}\text { Variável dependente: } \\
\text { média aritmética simples } \\
\text { das notas nas quatro } \\
\text { provas objetivas do Enem } \\
\mathbf{2 0 0 9} \text { ou 2010 }\end{array}$ & $\begin{array}{c}\text { (1) } \\
\text { Diferenças entre } \\
\text { médias (sem } \\
\text { controles) }\end{array}$ & $\begin{array}{c}\text { (2) } \\
\text { Diferenças entre } \\
\text { regressão (sem } \\
\text { controles) }\end{array}$ & $\begin{array}{c}\text { Modelo com } \\
\text { controles }\end{array}$ \\
\hline Grupo 1 (S-S) & $-20,799^{* * *}$ & $-20,403 * * *$ & $-4,087^{* * *}$ \\
\hline Grupo 2 (S-N) & $(0,7795)$ & $(0,8386)$ & $(0,765)$ \\
\hline Grupo 3 (N-S) & $-25,355^{* * *}$ & $-23,834 * *$ & $-8,787^{* * *}$ \\
\hline
\end{tabular}

2 As informações relativas à escolaridade dos pais, localização da residência e dependência administrativa das escolas durante os ensinos fundamental e médio foram consideradas como uma proxy do nível socioeconômico. Não pudemos incluir como proxy do nível socioeconômico a ocupação dos pais e a renda familiar per capita, em razão da ausência dos itens de ocupação e das dificuldades para se compatibilizar as informações de renda familiar e de número de habitantes no domicílio entre os questionários do Enem 2009 e 2010, já apontadas por outros pesquisadores (Alves; Soares; Xavier, 2014). 
TABELA 6

\section{REGRESSÃO LINEAR MÚLTIPLA DOS FATORES ASSOCIADOS AO DESEMPENHO NO ENEM ENTRE INGRESSANTES EM LICENCIATURAS - BRASIL - 2010/2011}

\begin{tabular}{|c|c|c|c|}
\hline \multirow[b]{2}{*}{$\begin{array}{l}\text { Variável dependente: } \\
\text { média aritmética simples } \\
\text { das notas nas quatro } \\
\text { provas objetivas do Enem } \\
2009 \text { ou } 2010\end{array}$} & $(1)$ & (2) & (3) \\
\hline & $\begin{array}{c}\text { Diferenças entre } \\
\text { médias (sem } \\
\text { controles) }\end{array}$ & $\begin{array}{l}\text { Diferenças entre } \\
\text { médias - amostra } \\
\text { regressão (sem } \\
\text { controles) }\end{array}$ & $\begin{array}{l}\text { Modelo com } \\
\text { controles }\end{array}$ \\
\hline \multirow{2}{*}{ Realizou Enem 2009} & & & $-5,944^{* * *}$ \\
\hline & & & $(0,2729)$ \\
\hline \multirow{2}{*}{ Sexo masculino } & & & $28,476^{* * *}$ \\
\hline & & & $(0,2672)$ \\
\hline \multirow{2}{*}{ Cor/Raça branca ou amarela } & & & $9,864 * * *$ \\
\hline & & & $(0,2719)$ \\
\hline \multirow{2}{*}{ Não solteiro } & & & $5,574^{* * *}$ \\
\hline & & & $(0,4087)$ \\
\hline \multirow{2}{*}{ Idade (ano) } & & & $-0,257 * * *$ \\
\hline & & & $(0,0228)$ \\
\hline \multirow{2}{*}{ Residência na área rural } & & & $-14,23 * * *$ \\
\hline & & & $(0,3813)$ \\
\hline \multirow{2}{*}{ Cursou EF na rede privada } & & & $24,692 * * *$ \\
\hline & & & $(0,3615)$ \\
\hline \multirow{2}{*}{ Cursou EM na rede privada } & & & $29,982 * * *$ \\
\hline & & & $(0,4172)$ \\
\hline \multirow{2}{*}{$\begin{array}{l}\text { Escolaridade da mãe - anos } \\
\text { iniciais do EF }\end{array}$} & & & $2,537 * * *$ \\
\hline & & & $(0,4558)$ \\
\hline \multirow{2}{*}{$\begin{array}{l}\text { Escolaridade da mãe - anos } \\
\text { finais do EF }\end{array}$} & & & $5,848^{* * *}$ \\
\hline & & & $(0,4608)$ \\
\hline \multirow{2}{*}{ Escolaridade da mãe - EM } & & & $7,634 * * *$ \\
\hline & & & $(0,5342)$ \\
\hline \multirow{2}{*}{ Escolaridade da mãe - ES } & & & $5,65^{* * *}$ \\
\hline & & & $(0,5744)$ \\
\hline \multirow{2}{*}{$\begin{array}{l}\text { Escolaridade do pai - anos } \\
\text { iniciais do EF }\end{array}$} & & & $1,159 *$ \\
\hline & & & $(0,419)$ \\
\hline \multirow{2}{*}{$\begin{array}{l}\text { Escolaridade do pai - anos } \\
\text { finais do } \mathrm{EF}\end{array}$} & & & $6,425^{* * *}$ \\
\hline & & & $(0,4345)$ \\
\hline \multirow{2}{*}{ Escolaridade do pai - EM } & & & $9,974^{* * *}$ \\
\hline & & & $(0,526)$ \\
\hline
\end{tabular}


TABELA 6

\section{REGRESSÃO LINEAR MÚLTIPLA DOS FATORES ASSOCIADOS AO DESEMPENHO NO ENEM ENTRE INGRESSANTES EM LICENCIATURAS - BRASIL - 2010/2011}

\begin{tabular}{|c|c|c|c|}
\hline \multirow[b]{2}{*}{$\begin{array}{l}\text { Variável dependente: } \\
\text { média aritmética simples } \\
\text { das notas nas quatro } \\
\text { provas objetivas do Enem } \\
2009 \text { ou } 2010\end{array}$} & (1) & (2) & (3) \\
\hline & $\begin{array}{c}\text { Diferenças entre } \\
\text { médias (sem } \\
\text { controles) }\end{array}$ & $\begin{array}{l}\text { Diferenças entre } \\
\text { médias - amostra } \\
\text { regressão (sem } \\
\text { controles) }\end{array}$ & $\begin{array}{c}\text { Modelo com } \\
\text { controles }\end{array}$ \\
\hline \multirow{2}{*}{ Escolaridade do pai - ES } & & & $9,104^{* * *}$ \\
\hline & & & $(0,5555)$ \\
\hline \multirow{2}{*}{ Constante } & $532,298 * * *$ & $533,598 * * *$ & $510,479 * * *$ \\
\hline & $(0,151)$ & $(0,1612)$ & $(0,768)$ \\
\hline Observações & 303.935 & 264.263 & 264.263 \\
\hline$\overline{R^{2}}$ & 0,0162 & 0,0169 & 0,2124 \\
\hline
\end{tabular}

Fonte: Elaboração própria com base em dados do Censo da Educação Básica 2009-2015, do Censo da Educação Superior 2010-2015 e do Enem 2009-2010.

Nota 1: Erros-padrão robustos a heterocedasticidade entre parênteses.

Nota 2: ** $\mathrm{p}<0.01,{ }^{*}$ * $\mathrm{p}<0.05,{ }^{*} \mathrm{p}<0.1$.

Nota 3: Informaçõs de sexo, cor/raça e rede privada no EM foram obtidas via questionário do Enem e, em caso de missing, complementadas com o Censo da Educação Superior.

Nota 4: Em todas as regressões há controles para a unidade da federação. Os coeficientes dessas dummies foram omitidos por uma questão de concisão.

Essa análise nos permite constatar, inicialmente, que os licenciandos dos grupos 1, 2 e 3 tendem a apresentar desempenho inferior ao do grupo 4, tomado como referência, na esteira do que já afirmamos (consultar colunas 1 e 2 da Tabela 6). Essas disparidades, contudo, são atenuadas quando se adota o modelo com controles para as características dos estudantes (coluna 3). Importante notar que a atenuação das diferenças entre os grupos 1, 2 e 3 em relação ao grupo 4 (referência) não se deve à redução da amostra, conforme atesta a equivalência dos coeficientes apresentados nas colunas 1 e 2. Parte da explicação do menor desempenho dos grupos 1, 2 e 3 deve-se a seu status socioeconômico menos favorecido. Após controladas as características dos estudantes, percebe-se que as diferenças entre o grupo 4 e os demais se reduzem para 4,1 pontos no caso do grupo 1, 8,8 pontos para o grupo 2 e 10,2 pontos para o grupo 3, valores estatisticamente significativos a 1\%. Quando se atenta para as variáveis de controle, nota-se que os maiores pesos incidem sobre o sexo (mais 28,5 pontos, se masculino), a dependência administrativa das escolas de ensino fundamental (mais 24,7 pontos, se na rede privada) e de ensino médio (mais 30,0 pontos, se na rede privada) que o licenciando frequentou e a localização da residência (menos 14,2 pontos, se na área rural). Em conjunto, esses resultados sugerem que, mesmo após controlar os fatores socioeconômicos, existem diferenças significativas no desempenho dos estudantes no momento de ingresso no curso de licenciatura, 
tendo os licenciandos, de alguma forma vinculados à docência, apresentado menor desempenho que os que não a exerceram (grupo de referência nas regressões). Entre os estudantes que se vincularam à docência em algum momento de suas trajetórias, os do grupo 3, que não eram docentes antes do ingresso no ES, apresentaram maior defasagem em relação ao grupo de referência (grupo 4).

\subsection{COMPARAÇÃO DA TRAJETÓRIA DURANTE O ENSINO SUPERIOR}

Nesta subseção serão analisadas as probabilidades de abandono e de conclusão em até cinco anos da licenciatura. Como visto na Tabela 2, pouco mais de $40 \%$ dos ingressantes nas licenciaturas em 2010 e 2011 haviam concluído o curso até o final de 2015. No entanto, há grande heterogeneidade entre os cursos. A Tabela 7 apresenta a proporção de ingressantes por curso e por grupo de licenciandos, bem como os concluintes e a taxa de conclusão até o final do período analisado no presente estudo.

TABELA 7

TAXA DE CONCLUSÃO DOS INGRESSANTES EM LICENCIATURAS, POR CURSO E GRUPO BRASIL - 2010/2011 (EM \%)

(continua)

\begin{tabular}{|c|c|c|c|c|c|c|c|}
\hline \multirow{2}{*}{ Área/Curso } & \multicolumn{6}{|c|}{ GRUPO } & \multirow{2}{*}{ Total } \\
\hline & 1 (S-S) & $2(\mathrm{~S}-\mathrm{N})$ & $1+2$ & $3(\mathrm{~N}-\mathrm{S})$ & $4(\mathrm{~N}-\mathrm{N})$ & $3+4$ & \\
\hline Pedagogia & 58,3 & 50,6 & 57,4 & 69,7 & 42,8 & 50,0 & 53,7 \\
\hline $\begin{array}{l}\text { Linguagens e } \\
\text { códigos }\end{array}$ & 47,4 & 37,4 & 46,1 & 65,1 & 34,6 & 38,6 & 41,6 \\
\hline Letras & 42,6 & 31,6 & 41,2 & 61,1 & 32,2 & 36,9 & 39,9 \\
\hline Artes & 55,3 & 48,5 & 54,7 & 67,8 & 32,9 & 42,0 & 46,7 \\
\hline Educação física & 54,9 & 42,4 & 52,2 & 70,9 & 36,7 & 39,9 & 42,6 \\
\hline Música & 33,7 & 40,3 & 35,0 & 54,9 & 33,0 & 35,4 & 37,3 \\
\hline Ciências humanas & 45,7 & 40,2 & 45,1 & 66,1 & 34,5 & 38,3 & 41,1 \\
\hline Filosofia & 47,3 & 42,3 & 46,7 & 66,9 & 36,0 & 39,8 & 42,6 \\
\hline Geografia & 50,1 & 42,9 & 49,3 & 70,1 & 37,4 & 41,7 & 44,8 \\
\hline História & 34,5 & 32,5 & 34,2 & 56,2 & 28,2 & 30,9 & 33,0 \\
\hline Ciências sociais & 41,0 & 34,7 & 40,3 & 59,6 & 27,5 & 30,6 & 33,1 \\
\hline $\begin{array}{l}\text { Ciências da } \\
\text { natureza }\end{array}$ & 36,1 & 33,5 & 35,8 & 55,8 & 27,2 & 29,6 & 31,6 \\
\hline Biologia & 40,8 & 36,2 & 40,1 & 63,6 & 34,8 & 37,1 & 39,0 \\
\hline Física & 25,3 & 36,4 & 26,3 & 65,7 & 28,7 & 31,5 & 33,7 \\
\hline Química & 41,3 & 23,1 & 39,2 & 29,7 & 7,9 & 10,4 & 12,4 \\
\hline
\end{tabular}


TABELA 7

TAXA DE CONCLUSÃO DOS INGRESSANTES EM LICENCIATURAS, POR CURSO E GRUPO BRASIL - 2010/2011 (EM \%)

\begin{tabular}{|c|c|c|c|c|c|c|c|}
\hline \multirow{2}{*}{ Área/Curso } & \multicolumn{6}{|c|}{ GRUPO } & \multirow{2}{*}{ Total } \\
\hline & 1 (S-S) & $2(\mathrm{~S}-\mathrm{N})$ & $1+2$ & $3(N-S)$ & $4(\mathrm{~N}-\mathrm{N})$ & $3+4$ & \\
\hline $\begin{array}{l}\text { Matemática e } \\
\text { computação }\end{array}$ & 31,9 & 26,8 & 31,3 & 53,9 & 20,0 & 24,6 & 27,8 \\
\hline Matemática & 31,5 & 28,0 & 31,1 & 54,7 & 19,5 & 24,5 & 28,0 \\
\hline Computação & 34,3 & 20,0 & 32,4 & 37,8 & 24,2 & 25,5 & 26,5 \\
\hline Total & 52,9 & 45,3 & 52,0 & 66,6 & 35,3 & 41,1 & 44,8 \\
\hline
\end{tabular}

Fonte: Elaboração própria com base em dados do Censo da Educação Básica 2009-2015 e do Censo da Educação Superior 2010-2015.

Nota: A proporção total de licenciados, 44,8\%, difere do obtido na Tabela 2, pois aqui foram desconsiderados casos de não identificação do curso.

Em geral, a taxa de conclusão das licenciaturas é maior para o grupo 3, seguido dos grupos 1, 2 e 4, respectivamente. Essa ordem só é levemente diferente em poucos cursos: música, química, letras e computação. Sob essa óptica, pedagogia tem a maior taxa de conclusão $(53,7 \%)$ independentemente do grupo analisado, e os cursos da área de matemática e computação possuem as menores taxas de conclusão das licenciaturas $(27,8 \%)$, também independentemente do grupo analisado. O curso de licenciatura com menores taxas de conclusão entre os que ingressaram em 2010 ou 2011 é química, com 12,4\% no geral, mas, no caso dos indivíduos que já exerciam a docência ao ingressar no curso, a taxa de conclusão é bem mais elevada, 39,2\%. Esse é o curso em que a diferença entre as taxas de conclusão de docentes e não docentes é mais expressiva.

O abandono ao longo do curso é uma característica marcante do ensino superior brasileiro. Para melhor analisar os fatores associados ao abandono, optou-se por regressões que também serão utilizadas para melhor compreender a probabilidade de conclusão do curso em até cinco anos.

A Tabela 8 apresenta análise sobre os fatores que estão associados à maior probabilidade de conclusão da licenciatura em até cinco anos após o ingresso. Os resultados mostram que atuar como docente em sala de aula antes do ingresso na licenciatura está associado a uma menor chance de se concluir o curso até 2014 (menos 1,9 pontos percentuais - p.p.). Entretanto, quem atuou na docência ao longo do curso de licenciatura apresenta maior probabilidade de conclusão do curso (14,0 p.p.). Quando se controla as características sociodemográficas dos estudantes e as características das instituições em que cursam a licenciatura, percebem-se pequenas mudanças desses coeficientes, com os licenciandos que estavam lecionando previamente com probabilidade condicional de conclusão do curso 3,0 p.p. inferior aos que não lecionavam e os que lecionaram durante a licenciatura apresentando probabilidade condicional 10,9 p.p. superior de concluir o curso até 2014 em relação aos que não lecionaram. 
Esses resultados são qualitativamente semelhantes quando se comparam estudantes do mesmo curso, mesma instituição e mesmo turno, conforme indica o modelo com efeito fixo de "turma".

Ademais, a tabela mostra que os modelos estimados permitem concluir que o exercício da docência ao longo do curso de licenciatura reduz drasticamente a probabilidade de abandono, tudo o mais constante, em 9,7 p.p., quando controladas as características sociodemográficas dos estudantes e de seu curso. Essa constatação se mantém mesmo quando se comparam estudantes de mesmo curso, instituição e turno (menos 10,4 p.p.). Por outro lado, ter atuado como docente imediatamente antes do ingresso na licenciatura associa-se à probabilidade 5,2 p.p. maior de abandonar o curso e, ao se comparar estudantes do mesmo curso, instituição e turno, à probabilidade 5,7 p.p. maior de abandonar a licenciatura.

Os licenciandos de cursos presenciais menos frequentemente concluíram o curso até 2014 (menos 2,7 p.p.) e mais frequentemente o abandonaram (12,7 p.p.); cursos em instituições públicas são menos abandonados (menos 8,8 p.p.), mas seus licenciandos apresentaram menor probabilidade de concluir o curso até 2014 (menos 11,9 p.p.), implicando maiores custos ao curso. Entre as instituições públicas, os cursos a distância apresentam taxa de conclusão maior, mas também taxa de abandono mais elevada.

Estudantes do sexo masculino possuem menor probabilidade de concluir o curso (menos 7,8 p.p.) e maior probabilidade de abandono (mais 5,5 p.p.). Quanto maior a idade de ingresso no curso, maiores são as chances tanto de conclusão quanto de abandono, indicando um decréscimo da protelação do curso à medida que a idade cresce. Esses achados mostram que os licenciandos que estudaram o EM em escola privada apresentam probabilidade 6,2 p.p. menor de concluir o curso até 2014 do que os que estudaram em escola pública, e possuem maior probabilidade de abandonar o curso (2,2 p.p.), tudo o mais constante. No escopo deste estudo, não foi possível averiguar se essa maior frequência do abandono se deve a troca de curso. 


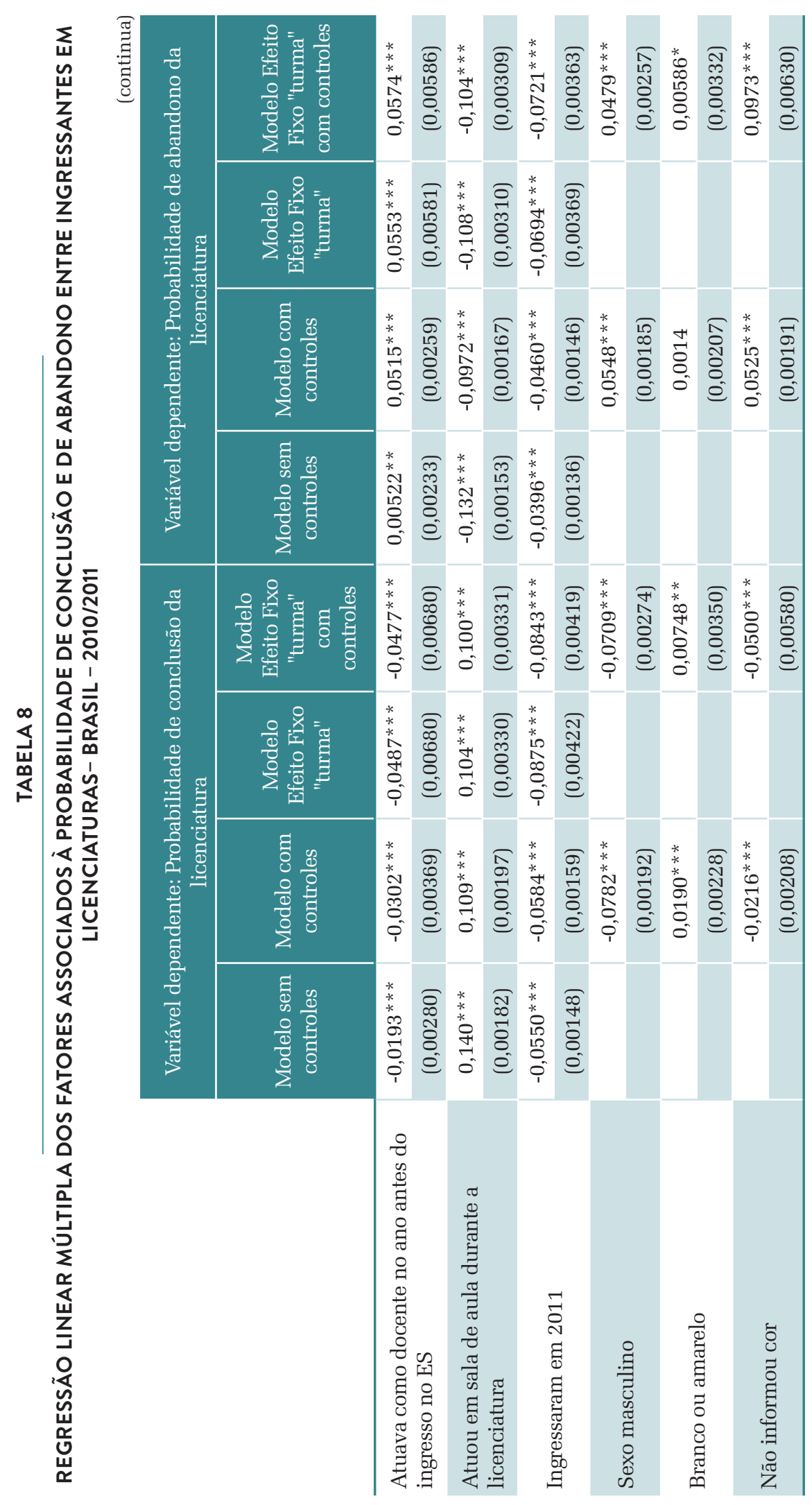




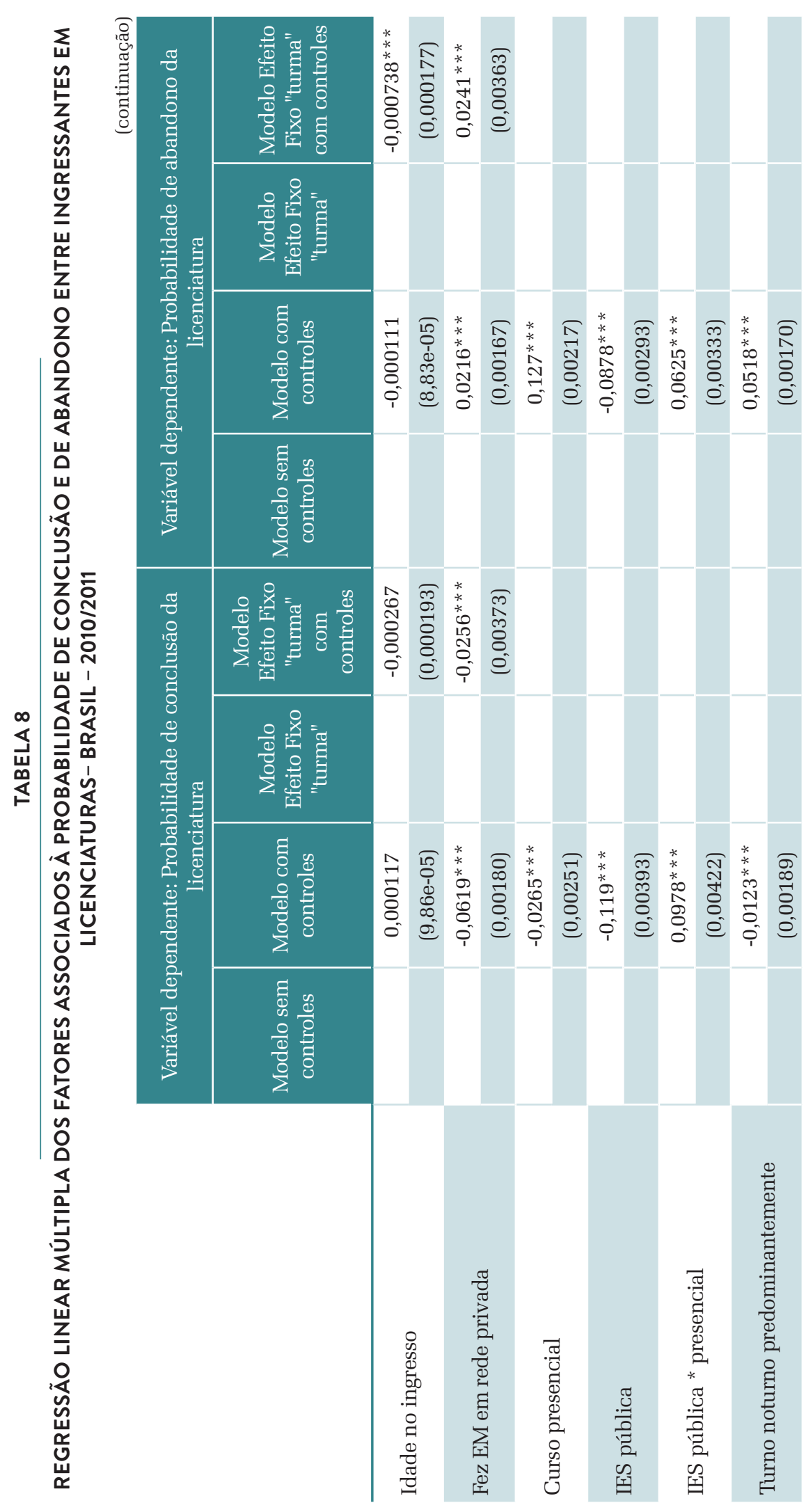




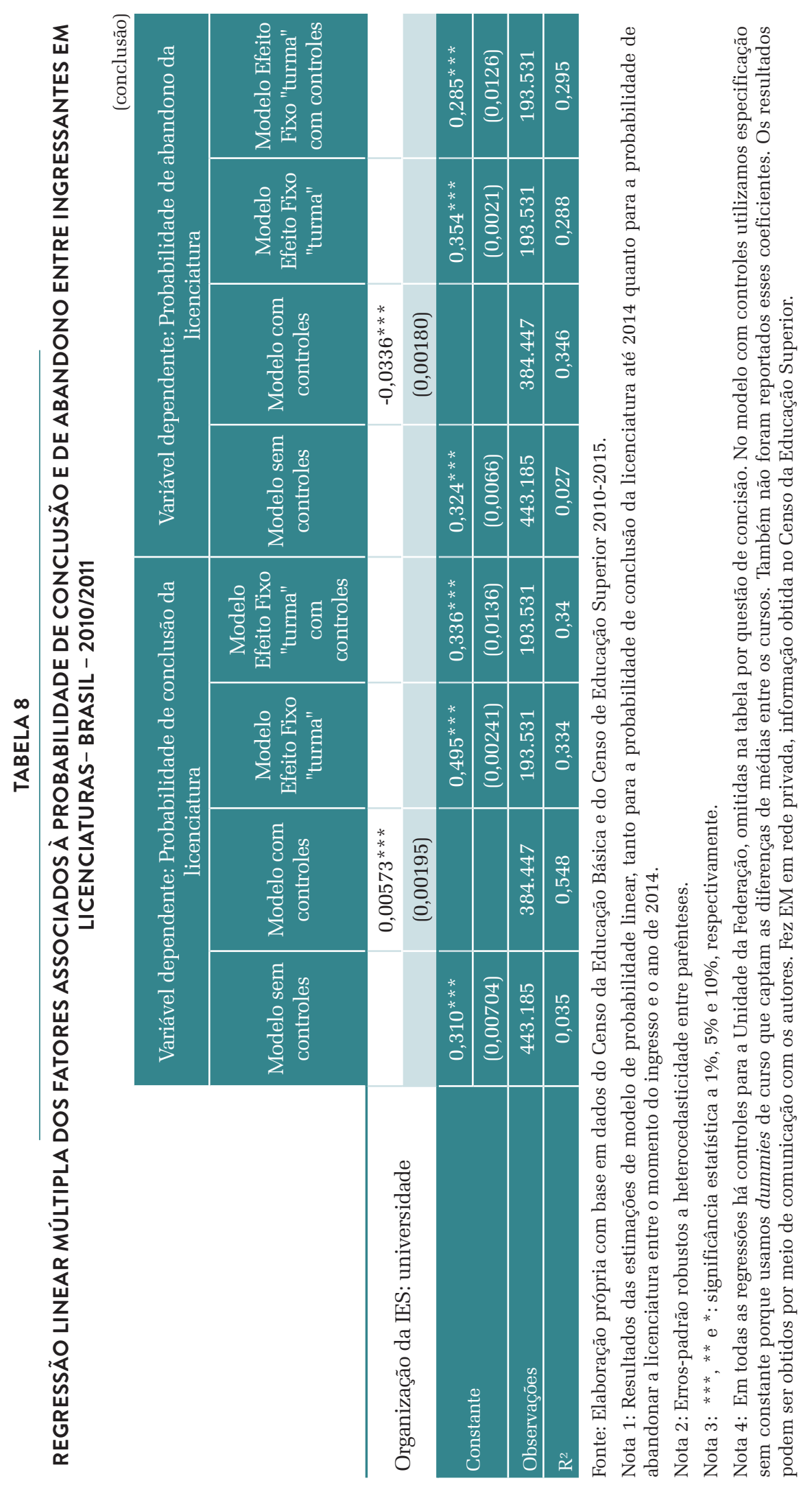




\subsection{COMPARAÇÃO DO DESEMPENHO AO FINAL DO ENSINO SUPERIOR}

Nesta subseção são apresentadas as comparações entre os quatro grupos de licenciandos no que se refere ao desempenho ao final do ES, com base nos resultados do Enade, dado que os estudantes atingiram o último ano do curso em 2014, independentemente do ano de ingresso, se 2010 ou 2011. A prova do Enade de 2014 está estruturada em dois componentes: o primeiro, comum a todos os cursos, e o segundo, específico de cada uma das áreas (cursos) avaliadas. Nas licenciaturas, o componente específico possui itens que averiguam os conhecimentos dos estudantes em didática, prática didática e conteúdo específico da área ou curso avaliado.

A Tabela 9 mostra os resultados das regressões cuja variável dependente é a nota no componente de formação geral do Enade. Os resultados da regressão (coluna 1) correspondem a simples diferenças de médias entre o grupo correspondente e o grupo 4, tomado como referência, medidas em desvio-padrão (dp) da distribuição de notas de todos os estudantes da amostra que fizeram o Enade 2014. Verifica-se que o grupo 4 apresenta a maior nota média no componente de formação geral. Os estudantes que não se engajaram na atividade docente possuem maior desempenho em conhecimentos gerais do que os que já eram ou se tornaram docentes após ingressar na licenciatura em 2010 ou 2011. O grupo 3, formado pelos estudantes que não eram docentes antes do ingresso no ES, mas se tornaram posteriormente, obteve nota média 0,09 dp inferior à média do grupo 4. Já o grupo 1 apresentou média 0,19 dp abaixo da média do grupo 4 enquanto o grupo 2 apresentou desempenho ainda inferior, com $0,25 \mathrm{dp}$ menos que a média. Ao se controlar algumas características observadas dos estudantes, de suas famílias e do curso, essas diferenças se reduzem para 0,03; 0,04; e 0,12 dp, respectivamente (veja coluna 3), indicando que a maior parte das diferenças de desempenho dos grupos deve-se a diferenças nos perfis sociodemográficos ou características de seus cursos. A variável que mais se destaca como explicativa do diferencial de notas é a que indica se o estudante estuda em IES pública (0,32 dp). Entre as características sociodemográficas analisadas, destacam-se, em termos de poder de explicação do desempenho no Enade, ser do sexo masculino (0,15 dp), e características associadas ao status socioeconômico do estudante, tais como a mãe ter pelo menos o ensino médio $(0,11 \mathrm{dp})$ e a renda familiar per capita $(0,05 \mathrm{dp}$ para cada salário mínimo a mais em média). 


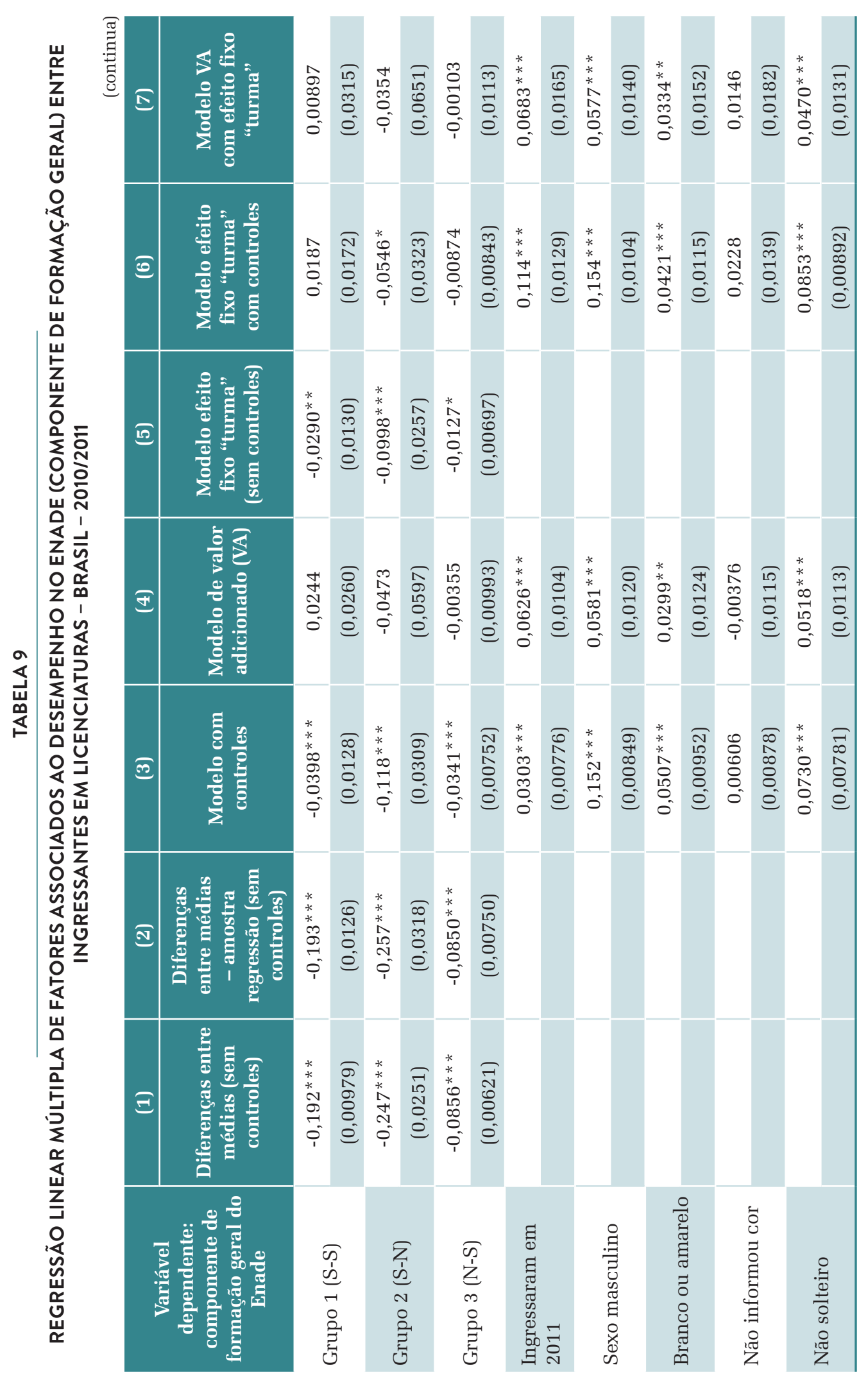




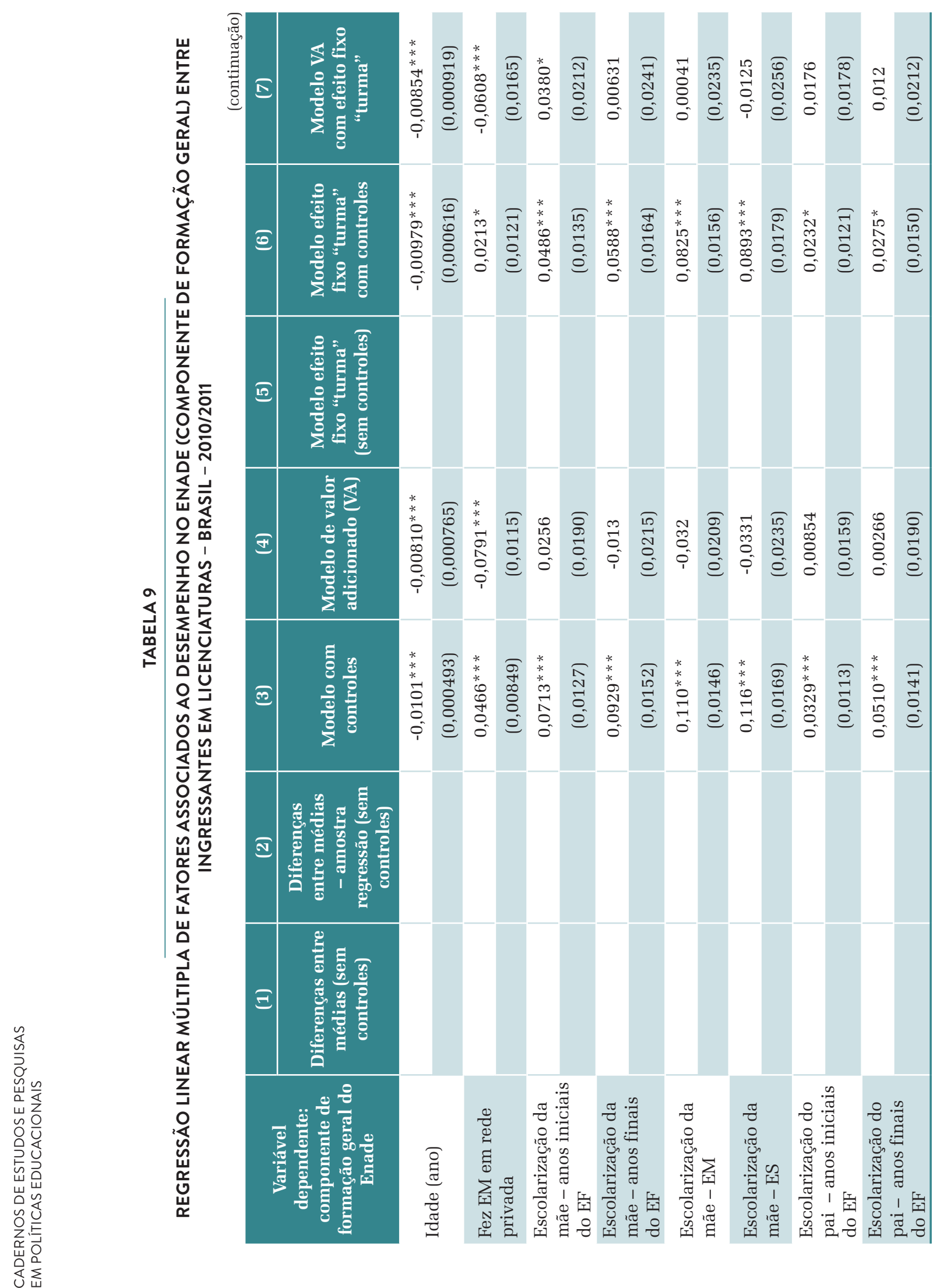




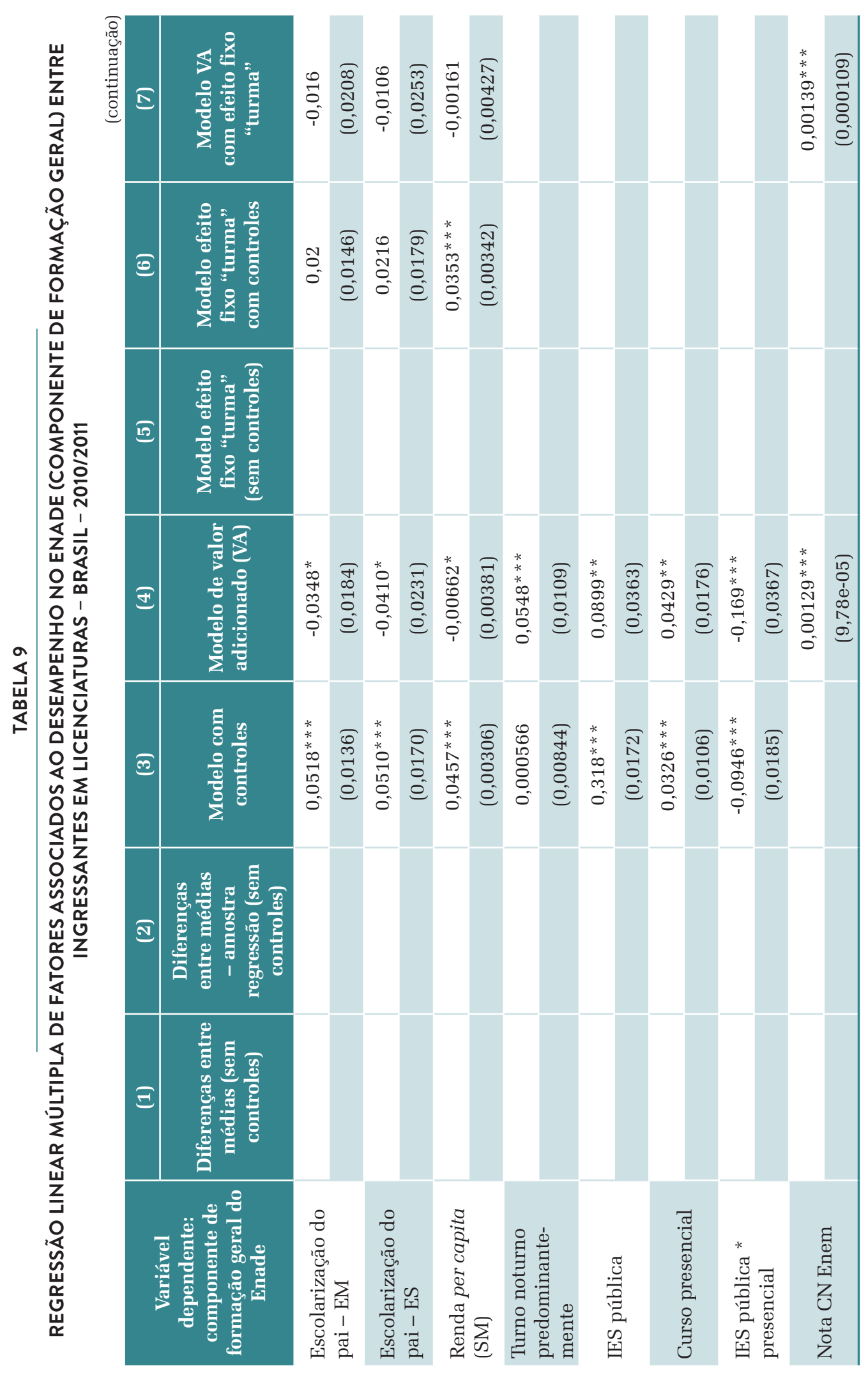




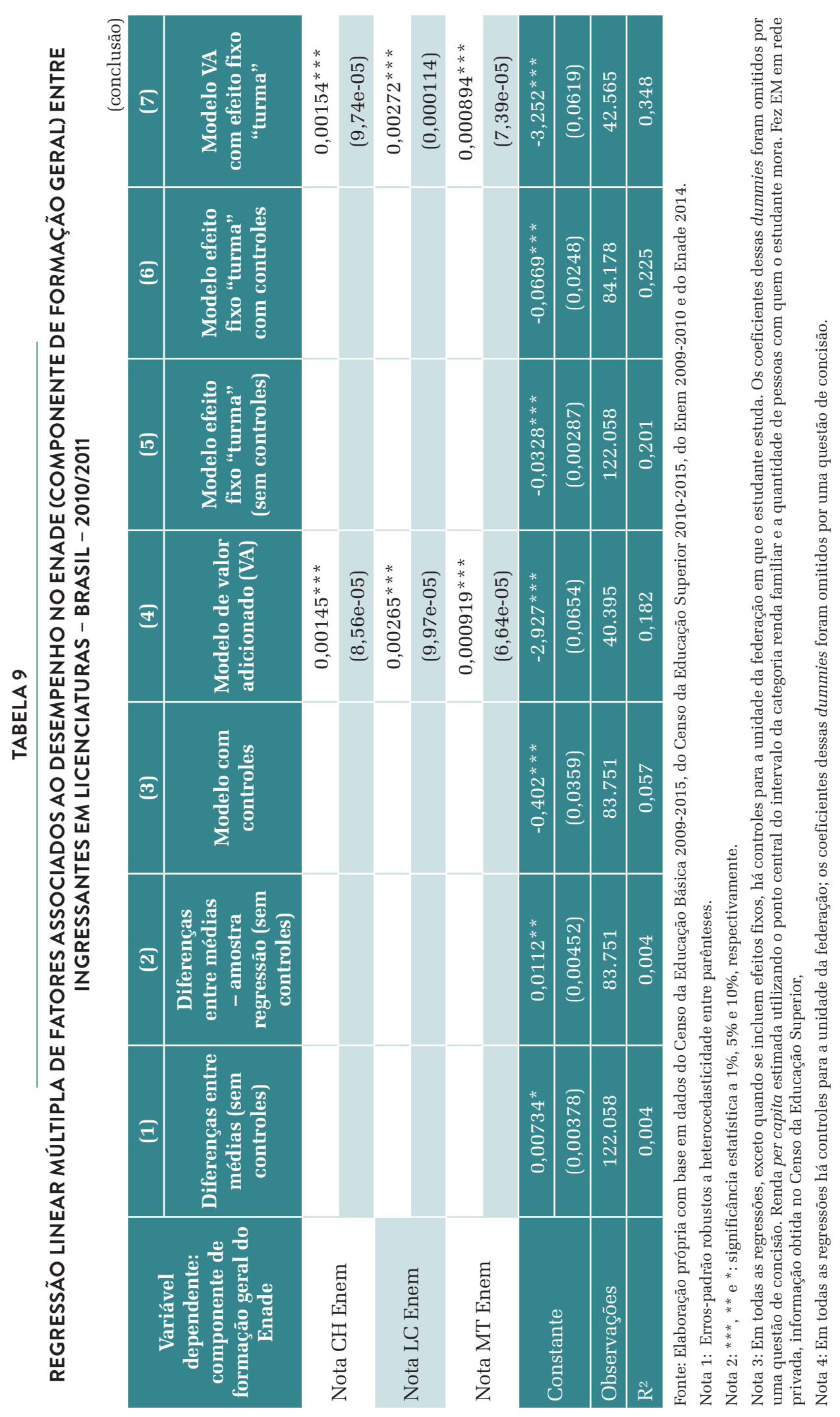


Quando se controla o desempenho dos estudantes no Enem prestado imediatamente antes do ingresso no curso, as diferenças entre os grupos desaparecem, isto é, os coeficientes das variáveis indicadoras, que marcam a diferença da média desses grupos em relação ao grupo de referência, ficam estatisticamente insignificantes (coluna 4). Esse resultado indica que o diferencial entre os grupos, no que se refere ao componente de formação geral do Enade, se explica já pelo diferencial de desempenho no Enem. Nesse caso, destacam-se os coeficientes das seguintes variáveis: estudar em IES pública (0,09 dp), ter ingressado no curso superior em 2011, ou seja, ter concluído o curso em menos tempo, e ser do sexo masculino (ambos com 0,06 dp).

A coluna 5 apresenta as diferenças de médias entre os grupos, controlando o curso, a instituição e o turno em que o estudante fez a licenciatura. Intuitivamente é como se estivéssemos comparando as médias dos grupos entre estudantes colegas de curso na mesma instituição e local. Percebe-se que os coeficientes das variáveis indicadoras de pertencimento a cada um dos grupos caem, permanecendo significantes. No entanto, ao se incluírem variáveis de controle no modelo, as diferenças de desempenho entre os grupos de estudantes caem e tornam-se estatisticamente não diferentes de zero, exceto para o grupo 2 que permanece significante a $10 \%$. Novamente, ao se incluírem as notas no Enem, as diferenças entre os grupos desaparecem, reafirmando os fatos de que os estudantes com vinculação à docência têm menor desempenho no componente de formação geral do Enade, mesmo quando se comparam indivíduos vinculados a um mesmo curso e instituição e de que este menor desempenho está associado ao seu perfil sociodemográfico.

Ao se comparar os resultados apresentados na coluna $3 \mathrm{com}$ os da coluna 6 percebe-se que os estudantes do grupo 4 possuem maior desempenho no exame de conhecimento geral, mesmo levando-se em conta as diferenças em termos de características sociodemográficas e do tipo de instituição em que estudam. Ao compararmos estudantes de uma mesma instituição, essas diferenças deixam de ser estatisticamente significantes. Conclui-se que os indivíduos do grupo 4, em média, estudam em instituições cujos estudantes possuem maior desempenho em termos de conhecimento geral, enquanto os que se vinculam de algum modo a docência estudam mais frequentemente em instituições ou turmas que possuem estudantes de menor desempenho médio em formação geral. No que diz respeito à medida de valor adicionado ao longo da licenciatura, não se pode rejeitar a hipótese de que não haja diferença entre os quatro grupos de estudantes, comparados no agregado ou apenas entre os colegas de mesma instituição, curso e turno ("turma”). 


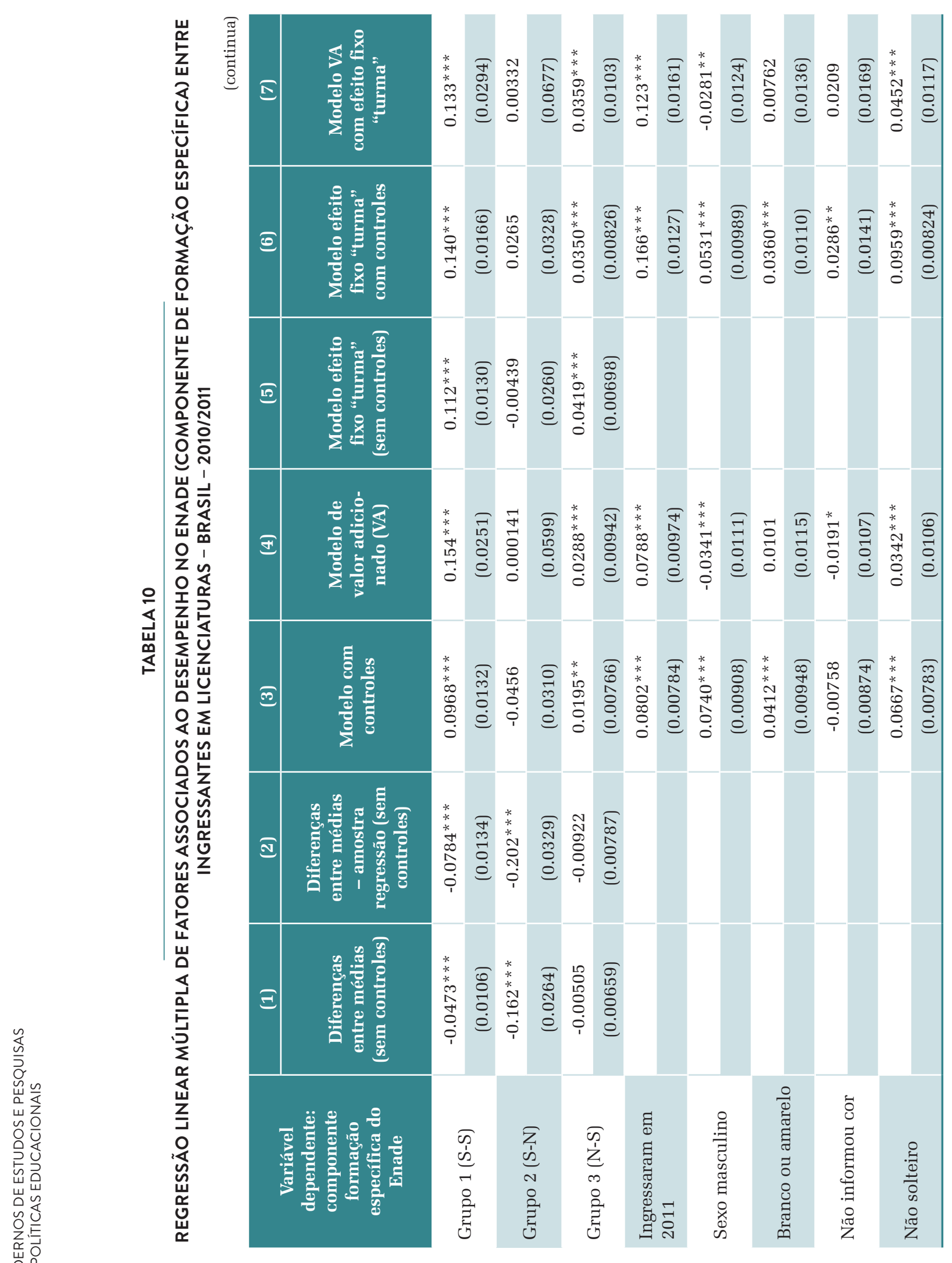




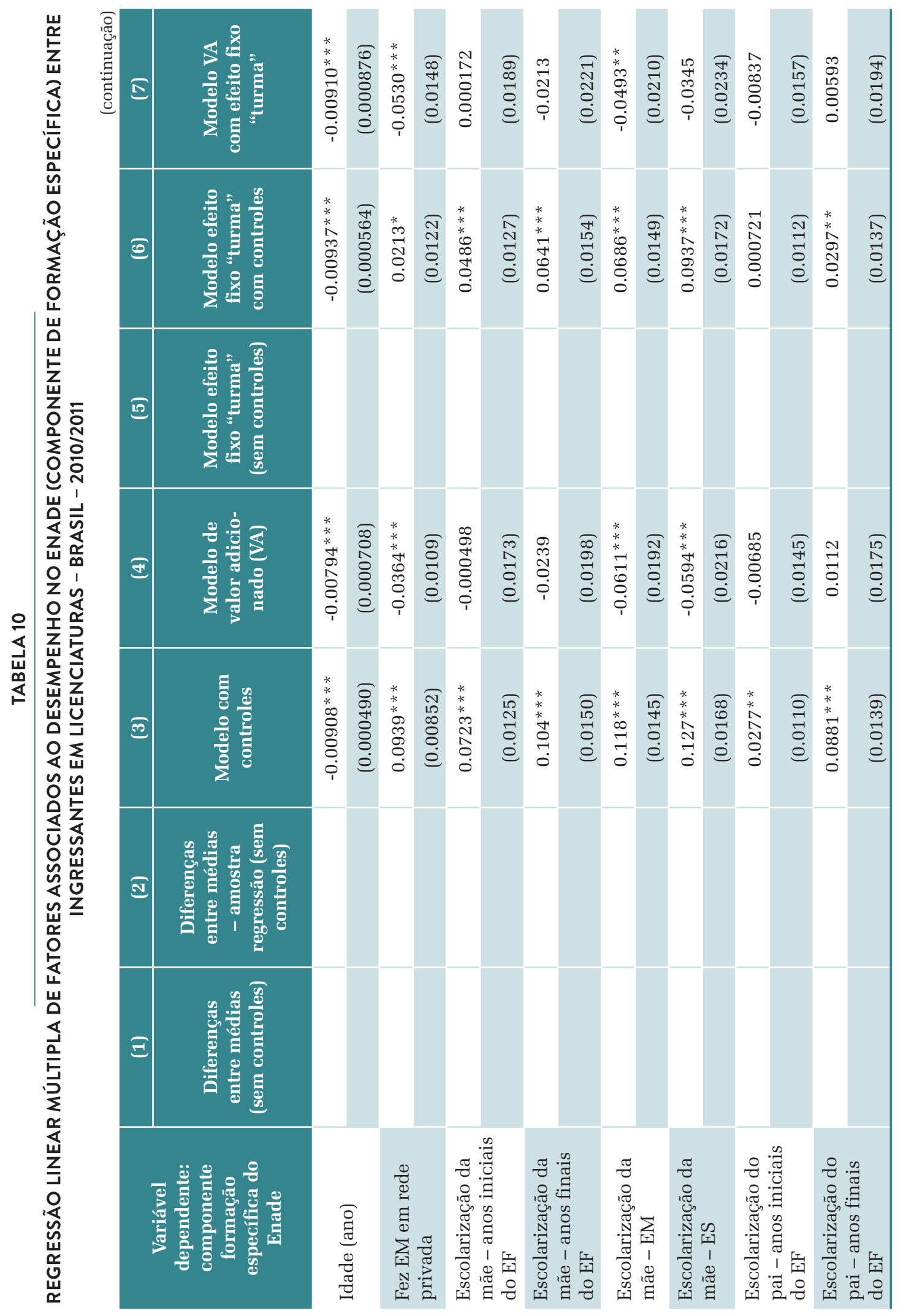




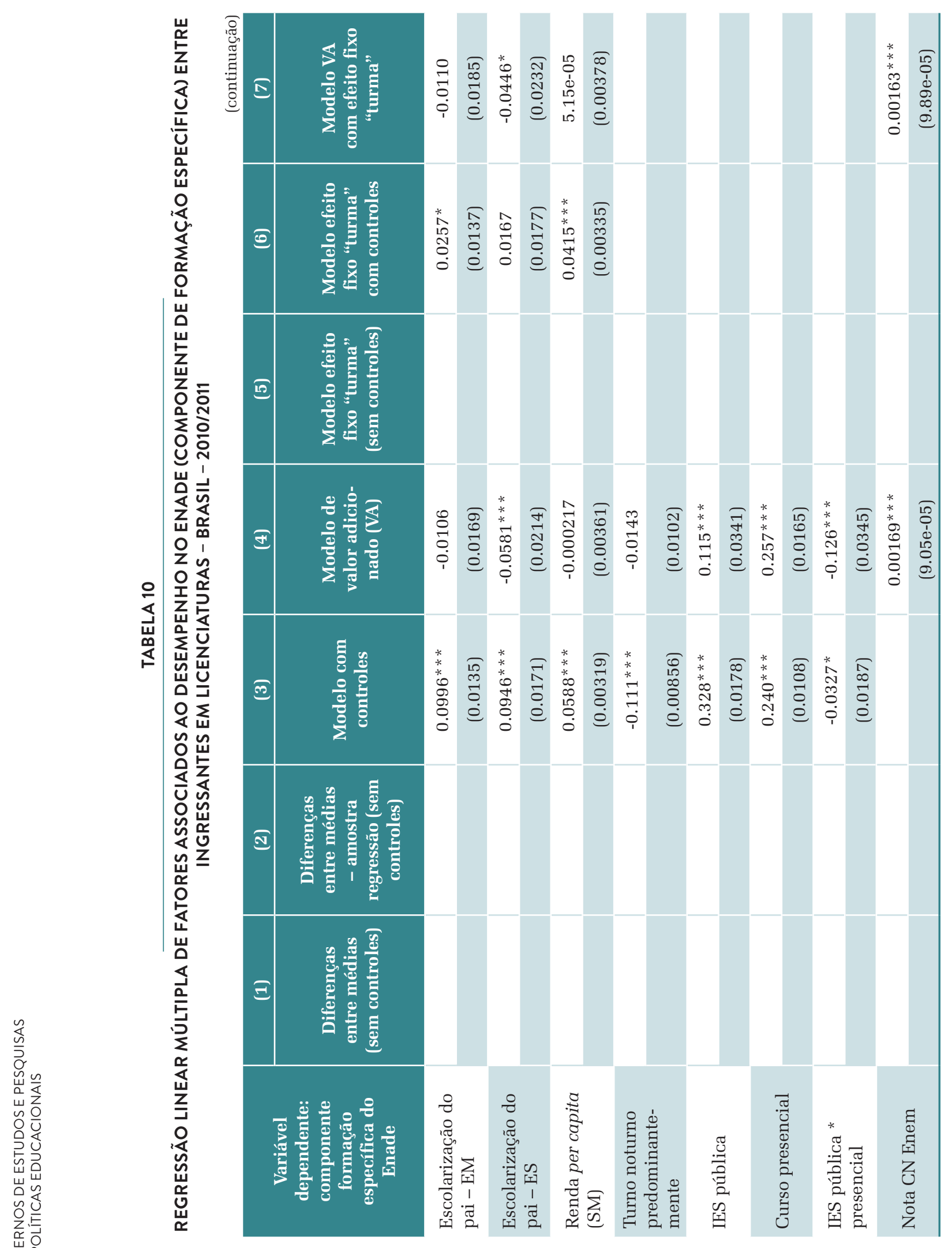




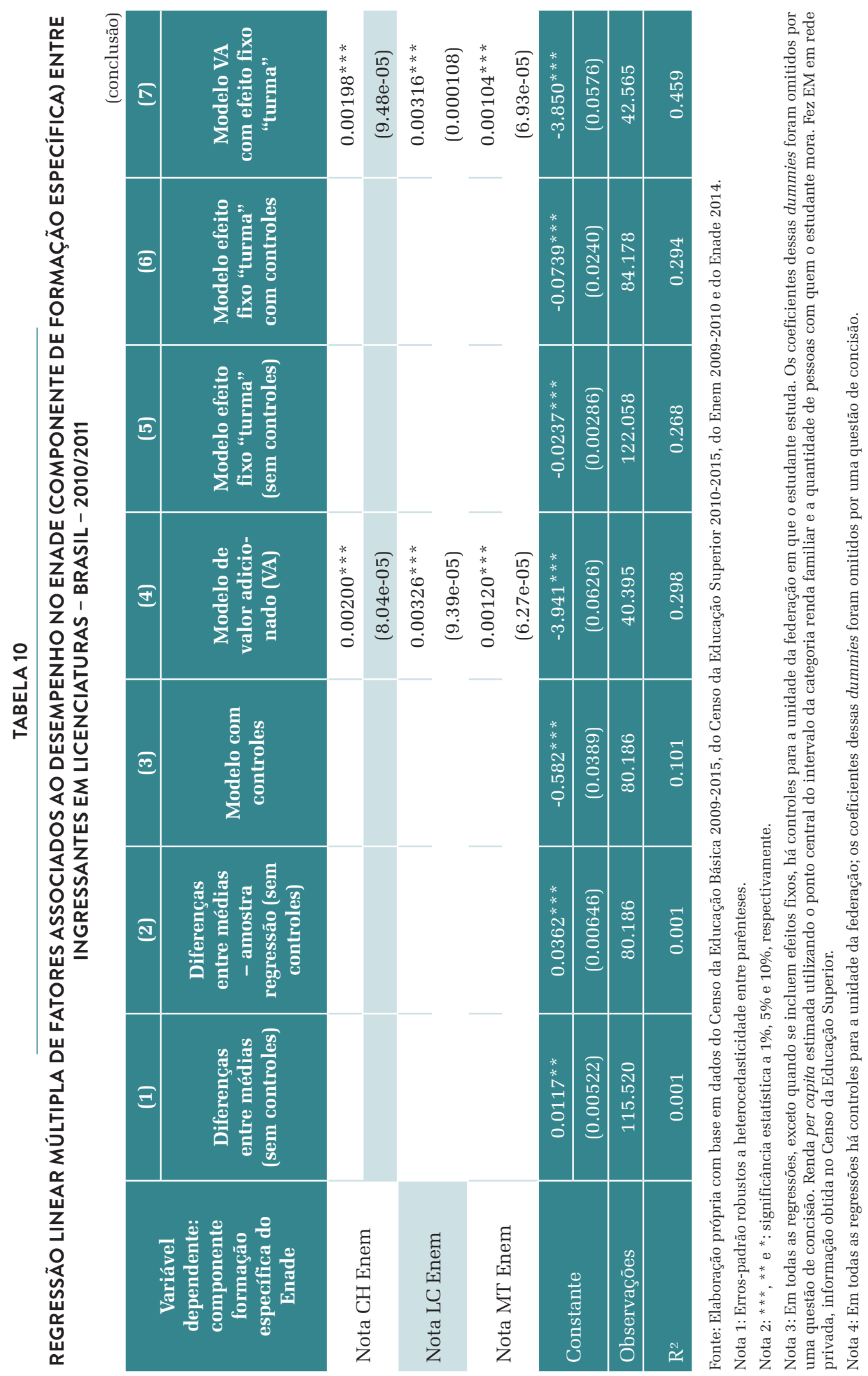


Já no que tange ao componente de conhecimento específico do Enade, os resultados são um pouco distintos dos apresentados no parágrafo anterior. Em que pese o fato de em média os estudantes dos grupos 1 e 2 possuírem também menor desempenho médio na prova de conhecimentos específicos (colunas 1 e 2), quando se controla as características sociodemográficas dos estudantes e as características das IES e dos cursos essa relação se inverte, o grupo 1 apresenta desempenho 0,10 dp superior e, o grupo 3, 0,02 dp superior à média do grupo 4 (coluna 3). Os modelos que consideram os efeitos fixos de instituição, curso e turno ("turma") indicam diferença ainda maior entre o desempenho dos grupos 1 e 3 em relação ao grupo 4: 0,14 dp e 0,035 $\mathrm{dp}$, respectivamente (coluna 6). Quando se incluem as notas do Enem no modelo, sem efeitos fixos de "turma", o diferencial de desempenho cresce atingindo 0,15 dp e 0,03 $\mathrm{dp}$, respectivamente (coluna 4), indicando que, ao se comparar os diferentes grupos de estudantes que apresentavam características semelhantes em termos sociodemográficos e de desempenho no Enem, os que exerceram a docência durante a licenciatura apresentaram desempenho ainda maior. Já no modelo com efeitos fixos de "turma" os valores dos coeficientes ficam semelhantes aos estimados sem controlar a nota no Enem (coluna 7 versus coluna 6), indicando que, por estarem na mesma "turma", o desempenho no Enem não explica o diferencial de desempenho entre os grupos no Enade.

Uma possível explicação para o maior desempenho, uma vez controladas as características dos estudantes e das instituições em que estudam, em termos de conhecimentos específicos dos que estão a exercer a docência em escolas da educação básica ao longo da licenciatura pode ser o fato de poderem ou necessitarem aplicar esses conhecimentos no dia a dia e de estarem submetidos a outras fontes de capacitação para a docência, seja pelo contato com colegas professores ou por se submeterem a eventos de capacitação continuada na rede em que atuam. Outra possibilidade é que os licenciandos que exercem a docência e já possuem diploma de curso superior têm mais interesse em desenvolver os conhecimentos específicos.

Nesse sentido, o tempo de experiência como docente e o fato de o estudante já possuir outro curso superior ou outra licenciatura podem contribuir positivamente para seus conhecimentos específicos. De fato, ao restringirmos a amostra apenas aos que exerciam a docência antes do ingresso na licenciatura em 2010 e 2011, fica demonstrada a associação entre o fato de o estudante já possuir curso superior anteriormente e o desempenho no Enade (veja Tabela 11). Os docentes que já possuíam curso superior ao ingressar na licenciatura em 2010 ou 2011 apresentaram média na prova de conhecimentos específicos 0,36 dp superior aos que não possuíam diploma de curso superior. Mesmo após controlar diversas características dos estudantes e das instituições e cursos, o coeficiente associado à posse prévia de diploma foi estimado em 0,14 dp, valor bastante alto quando se compara com os coeficientes dos demais fatores. Quanto maior o tempo de vigência do contrato como docente ao ingressar no ES, pior tende a ser o desempenho do estudante no Enade, mas, para quem já possuía diploma de nível superior, o efeito médio de cada ano adicional de experiência no cargo de docente no desempenho no exame se mostra positivo, mas significante estatisticamente a apenas $10 \%$. 
TABELA 11

FATORES ASSOCIADOS AO DESEMPENHO NO ENADE ENTRE DOCENTES COMPONENTE ESPECÍFICO - BRASIL

\begin{tabular}{|c|c|c|c|}
\hline $\begin{array}{l}\text { Variável dependente: } \\
\text { componente formação } \\
\text { específica do Enade }\end{array}$ & $\begin{array}{l}\text { Diferenças entre } \\
\text { médias (sem } \\
\text { controles) }\end{array}$ & $\begin{array}{l}\text { Diferenças entre } \\
\text { médias - amostra } \\
\text { regressão (sem } \\
\text { controles) }\end{array}$ & $\begin{array}{l}\text { Modelo com } \\
\text { controles }\end{array}$ \\
\hline \multirow{2}{*}{ Grupo 2 (S-N) } & $-0,0782^{* *}$ & $-0,0917^{* *}$ & $-0,112^{* * *}$ \\
\hline & $(0,0313)$ & $(0,0403)$ & $(0,0386)$ \\
\hline \multirow{2}{*}{ Possuía diploma ao ingressar } & $0,359 * * *$ & $0,373 * * *$ & $0,140 * * *$ \\
\hline & $(0,0348)$ & $(0,0454)$ & $(0,0447)$ \\
\hline \multirow{2}{*}{$\begin{array}{l}\text { Ano adicional no cargo docente } \\
\text { ao ingressar }\end{array}$} & $-0,00881^{* * *}$ & $-0,00878^{* * *}$ & $-0,00803^{* * *}$ \\
\hline & $(0,00193)$ & $(0,00251)$ & $(0,00241)$ \\
\hline \multirow{2}{*}{$\begin{array}{l}\text { Ano adicional cargo doc * } \\
\text { diploma ao ingressar }\end{array}$} & $0,0111^{* * *}$ & $0,00905^{*}$ & 0,00801 * \\
\hline & $(0,00377)$ & $(0,00491)$ & $(0,00455)$ \\
\hline Observações & 9.623 & 5.661 & 5.661 \\
\hline $\mathrm{R} 2$ & 0,05 & 0,061 & 0,192 \\
\hline
\end{tabular}

Fonte: Elaboração própria com base em dados do Censo da Educação Básica 2009-2015, do Censo da Educação Superior 2010-2015 e do Enade 2014.

Nota 1: Erros-padrão robustos a heterocedasticidade entre parênteses.

Nota $2: * * * * \mathrm{e}^{*}$ : significância estatística a 1\%, 5\% e 10\%, respectivamente.

Nota 3: Regressões utilizando subamostra de quem exercia docência ao ingressar na licenciatura em 2010 ou 2011 , isto é, os componentes dos grupos 1 e 2. Aqui o grupo de referência é o grupo 1. Em todos os três modelos apresentados foram acrescidos o tempo de vigência do contrato de trabalho como docente (Rais) e a informação se possuía curso superior obtida do Censo da Educação Básica, bem como a interação entre essas duas variáveis. No modelo com controles foram inseridos todos os controles utilizados nas regressões apresentadas nas tabelas anteriores.

\section{CONSIDERAÇÕES FINAIS}

Neste estudo, de caráter exploratório, utilizamos análises de quantitativos gerais e descritivas condicionadas a características individuais e institucionais para comparar o perfil e o desempenho de licenciandos, segundo o exercício ou não de docência, antes ou depois do ingresso em um curso superior em 2010 ou 2011. A despeito de sua abordagem preliminar, acredita-se que este texto ilumine questões acadêmica e politicamente relevantes para se pensar a formação docente no Brasil. Ressalta-se, como qualidade deste estudo, a elaboração de um painel longitudinal de relativa complexidade que cruza diferentes edições de cinco bases de dados distintas para a composição de um retrato rico e abrangente sobre o ingresso, a trajetória e a conclusão de cursos de licenciatura entre docentes e não docentes por todo o país. À guisa de conclusão, exploraremos alguns dos achados mais importantes. 
Os resultados deste estudo corroboram o achado da literatura que aponta que a carreira docente atrai os estudantes de licenciaturas de nível socioeconômico menos favorecido e com menor nível de conhecimentos gerais e desempenho no Enem (Louzano et al., 2010; Brasil.Inep, 2009; 2010; Gatti; Barretto, 2009; Alves et al., 2016; Iede, 2018). Os estudantes de licenciatura, que de algum modo estão vinculados à carreira docente, antes e/ou depois do ingresso no ES, menos frequentemente estudaram o EM em escolas privadas e também, com menos frequência, declaram-se brancos ou amarelos. Seus pais possuem menor escolaridade média e suas famílias menor renda per capita média. Os licenciandos e professores da educação básica mais frequentemente ingressam em pedagogia, cursam IES privadas e cursos a distância do que os licenciandos não docentes.

Como contribuição original, mediante junção da base longitudinal de docentes da educação básica do Censo da Educação Básica e da base longitudinal de estudantes de licenciaturas, este estudo revela que a maior taxa de conclusão (em até 5 anos) e a menor taxa de abandono da licenciatura são dos estudantes que exerciam ou vieram a exercer a docência depois do ingresso no curso. Outra contribuição deste artigo é a comparação entre desempenhos dos diferentes grupos de licenciandos ao final da graduação. Os estudantes com vinculação à docência apresentam menor desempenho no componente de formação geral do Enade, mesmo quando se comparam indivíduos de um mesmo curso e instituição, mas este menor desempenho está associado ao seu perfil sociodemográfico. Os estudantes que não se vinculam à docência, nem antes nem depois do ingresso no ES, em média, estudam em instituições e cursos cujos estudantes possuem maior desempenho em termos de formação geral, enquanto os que se vinculam, de algum modo, à docência estudam mais frequentemente em instituições ou turma que possuem estudantes de menor desempenho médio em formação geral.

Já no que se refere ao componente específico do Enade, em que pese o fato de, em média, os estudantes que exerciam a docência ao ingressar no ES possuírem também menor desempenho médio na prova de conhecimentos específicos, quando se controlam as características sociodemográficas dos estudantes e as características das IES e dos cursos, essa relação se inverte, isto é, esses estudantes passam a apresentar um desempenho maior na mesma prova. Quando se comparam licenciandos de uma mesma instituição e curso, os que possuem trajetória na docência apresentam desempenho médio no componente de conhecimentos específicos muito superior ao dos não docentes. Mostrou-se que o fato de o estudante já possuir outro curso superior ou outra licenciatura contribui positivamente para seus conhecimentos específicos e, nesse caso, o tempo de experiência como docente, ao contrário do caso em que os estudantes não possuem previamente curso superior, reforça o diferencial de desempenho. 
Entretanto, é preciso mencionar algumas limitações deste estudo. Por ter se concentrado sobre os ingressantes de 2010 e 2011, obteve-se um quantitativo bastante reduzido de licenciandos com participação nas edições anteriores do Enem, tendo em vista que o exame, até então, era bem menos representativo dos concluintes e egressos do ensino médio se comparado à atualidade. Apesar de os resultados do Enem serem condizentes com os do componente de conhecimento geral do Enade, seria preciso analisar com mais profundidade se essas amostras de estudantes que fizeram Enem e cujos desempenhos relativos analisados representaram bem o total de cada um dos grupos aqui discutidos. Ainda, apesar de apresentarmos indícios de possíveis explicações para o maior desempenho em termos de conhecimentos específicos no Enade dos que exercem a docência em escolas da educação básica ao longo da licenciatura, no âmbito deste estudo não foi possível apresentar conclusões muito assertivas sobre as hipóteses aventadas.

Estudos futuros poderão abordar de forma mais aprofundada, e talvez complementando com análises mais qualitativas, algumas hipóteses, tais como: (1) o maior interesse por parte dos docentes em relação a conhecimentos específicos; (2) as possibilidades de aplicação dos conhecimentos específicos no contexto da escola e da sala de aula; (3) a obtenção de conhecimento mediante outras fontes de capacitação para a docência, seja pelo contato com colegas professores ou por se submeterem a eventos de capacitação continuada na rede em que atuam; e (4) a hipótese de os já detentores de diploma de curso superior possuírem mais interesse em desenvolver os conhecimentos específicos ou terem adquirido mais conhecimentos, seja por maior aptidão ou por terem tido mais oportunidades de formação ao longo de sua trajetória até a conclusão da licenciatura em 2014. Por fim, a base de dados construída para a elaboração deste estudo pode e deverá ser mais explorada para investigar outras questões relevantes em relação à qualidade docente.

Outro ponto importante para subsidiar políticas de formação de professores é o fato de que parece que os indivíduos vinculados à docência possuem acesso a instituições cujos pares apresentam, em média, menor desempenho no Enade, em especial no componente de formação geral, mas também no componente de formação específica. Importa investigar se essas instituições com estudantes de maior desempenho formam docentes mais efetivos no que se refere à aprendizagem de seus alunos e se os docentes possuem acesso a instituições que fornecem melhor formação. A base utilizada neste artigo, caso complementada por outras bases de dados do Inep, possui o potencial de gerar subsídios nesse sentido. 


\section{REFERÊNCIAS}

AARONSON, D.; BARROW, L.; SANDER, W. Teachers and student achievement in the Chicago public high schools. Journal of Labor Economics, Chicago, v. 25, n. 1, p. 95-135, 2007.

ALVES, M. T. G.; SOARES, J. F.; XAVIER, F. P. Índice socioeconômico das escolas de educação básica brasileiras. Ensaio: Avaliação e Políticas Públicas em Educação, Rio de Janeiro, v. 22, n. 84, p. 671-704, 2014.

ALVES, R. et al. Ser ou não ser professor da Educação Básica?: salário esperado e outros fatores na escolha ocupacional de concluintes de licenciaturas. 2016. Mimeografado.

ARAUJO, R. S.; VIANNA, D. M. A carência de professores de ciências e matemática na Educação Básica e a ampliação de vagas no Ensino Superior. Ciência \& Educação, Bauru, v. 17, n. 4, p. 807-822, 2011.

BAUER, A.; CASSETTARI, N.; OLIVEIRA, R. P. Políticas docentes e qualidade da educação: uma revisão da literatura e indicações de política. Ensaio: Avaliação e Políticas Públicas em Educação, Rio de Janeiro, v. 25, n. 97, p. 943-970, out./dez. 2017.

BRASIL. Instituto Nacional de Estudos e Pesquisas Educacionais Anísio Teixeira (Inep). Quem quer ser professor no Brasil: o que o Enem nos diz? Na Medida: Boletim de Estudos Educacionais do Inep, Brasília, ano 1, n. 3, p. 5-9, set. 2009.

BRASIL. Instituto Nacional de Estudos e Pesquisas Educacionais Anísio Teixeira (Inep). Os salários dos professores da rede pública brasileira são atrativos? $\mathrm{Na}$ Medida: Boletim de Estudos Educacionais do Inep, Brasília, ano 2, n. 5, p. 10-12, maio 2010.

BRASIL. Instituto Nacional de Estudos e Pesquisas Educacionais Anísio Teixeira (Inep). Relatório do $2^{\circ}$ ciclo de monitoramento das metas do Plano Nacional de Educação: 2018. Brasília: Inep, 2018. Disponível em: < http://portal.inep.gov.br/ documents/186968/485745/RELAT\%C3\%93RIO+DO+SEGUNDO+CICLO+DE+ MONITORAMENTO+DAS + METAS +DO+PNE+2018/9a039877-34a5-4e6a-bcfdce93936d7e60?version=1.17> . Acesso em: 23 jul. 2018.

CHETTY, R.; FRIEDMAN, J. N.; ROCKOFF, J. E. Measuring the Impacts of Teachers I: evaluating bias in teacher value-added estimates. American Economic Review, Princeton, N.J., v. 104, n. 9, p. 2593-2632, 2014a. 
CHETTY, R.; FRIEDMAN, J. N.; ROCKOFF, J. E. Measuring the Impacts of Teachers II: teacher value-added and student outcomes in adulthood. American Economic Review, Princeton, N.J., v. 104, n. 9, p. 2633-2679, 2014b.

CORCORAN, S. P.; EVANS, W. N.; SCHWAB, R. M. Women, the Labor Market, and the Declining Relative Quality of Teachers. Journal of Policy Analysis and Management, [New York, N.Y.], v. 23, n. 3, p. 449-470, 2004.

GATTI, B. A. Os professores e suas identidades: o desvelamento da heterogeneidade. Cadernos de Pesquisa, São Paulo, n. 98, p. 85-90, ago, 1996.

GATTI, B.; BARRETO, E. (Coord.). Professores do Brasil: impasses e desafios. Brasília: UNESCO, 2009. Disponível em: < http://unesdoc.unesco.org/ images/0018/001846/184682por.pdf>. Acesso em: 28 set. 2016.

GATTI, B.; ESPOSITO, Y.; SILVA, R. N. Características de professores (as) de $1^{\circ}$ grau no Brasil: perfil e expectativas. Educação \& Sociedade, Campinas, v. 15, n. 48, p. 248-260, ago. 1994.

HANUSHEK, E.; WOESSMANN, L. Do better schools lead to more growth?: cognitive skills, economic outcomes, and causation. Journal of Economic Growth, Springer, v. 17, p. 267-321, Dec. 2012.

INTERDISCIPLINARIDADE E EVIDÊNCIAS NO DEBATE EDUCACIONAL (Iede). $O$ perfil dos jovens que esperam ser professores. São Paulo: Iede, 2018. Disponível em: $<$ http://www.portaliede.com.br/wp-content/uploads/2018/04/Estudo-do-Iede_Operfil-dos-jovens-que-esperam-ser-professores.pdf>. Acesso em: 3 ago. 2018.

LAZEAR. E. P. Teacher incentives. Swedish Economic Policy Review, [S.l.], n. 10, p. 179-214, 2003.

LOUZANO, P. et al. Quem quer ser professor?: atratividade, seleção e formação docente no Brasil. Estudos de Avaliação Educacional, São Paulo, v. 21, n. 47, p. 543-568, set./dez. 2010.

MORICONI, G. M. Medindo a eficácia dos professores: o uso de modelos de valor agregado para estimar o efeito do professor sobre o desempenho dos alunos. 2012. 115 f. Tese (Doutorado em Administração Pública) - Escola de Administração Pública de São Paulo, Fundação Getúlio Vargas, São Paulo, 2012.

PINTO, J. M. R. O que explica a falta de professores nas escolas brasileiras? Jornal de Políticas Educacionais, Curitiba, n. 15, p. 3-12, jan./jul. 2014. 
RABELO, R. P.; CAVENAGHI, S. Indicadores educacionais para formação de docentes: uso de dados longitudinais. Estudos de Avaliação Educacional, São Paulo, v. 27, n. 66, p. 816-850, set./dez. 2016.

RIVKIN, S.; HANUSHEK, E.; KAIN, J. Teachers, Schools and Academic Achievement. Econometrica, Chicago, v. 72, n. 2, p. 417-458, Mar. 2005.

ROCKOFF, J. The impact of individual teachers on student achievement: evidence from panel data. The American Economic Review, Nashville, Tenn., v. 94, n. 2, p. 247-252, 2004.

SILVA FILHO, G. A. Higher salaries, more teaching, better performance? The effects of the introduction of the minimum salary for teachers. 2016. Tese (Doutorado em Economia) - Escola de Economia de São Paulo, Fundação Getúlio Vargas, São Paulo, 2016.

SINGER, J.; WILLETT, J. Applied longitudinal data analysis: modeling change and event occurrence. New York: Oxford University Press, 2003. 